\title{
Article \\ Molecular Structure of Nickel Octamethylporphyrin-Rare Experimental Evidence of a Ruffling Effect in Gas Phase
}

\author{
Alexander E. Pogonin 1,*(D), Arseniy A. Otlyotov ${ }^{2,3}{ }^{(D}$, Yury Minenkov ${ }^{3,4}$, Alexander S. Semeikin ${ }^{5}$, \\ Yuriy A. Zhabanov ${ }^{2}$, Sergey A. Shlykov ${ }^{6}$ and Georgiy V. Girichev ${ }^{2, *}$
}

1 Department of Nanomaterials and Ceramic Technology, Ivanovo State University of Chemistry and Technology, Sheremetevsky Avenue 7, 153000 Ivanovo, Russia

2 Department of Physics, Ivanovo State University of Chemistry and Technology, Sheremetevsky Avenue 7, 153000 Ivanovo, Russia; arseney_otlyotov@mail.ru (A.A.O.); zhabanov@gmail.com (Y.A.Z.)

3 N.N. Semenov Institute of Chemical Physics of Russian Academy of Sciences, Kosygina Street 4, 119991 Moscow, Russia; Yury.Minenkov@chph.ras.ru

4 Joint Institute for High Temperatures, Russian Academy of Sciences, 13-2 Izhorskaya Street, 125412 Moscow, Russia

5 Department of Organic Chemistry, Ivanovo State University of Chemistry and Technology, Sheremetevsky Avenue 7, 153000 Ivanovo, Russia; semeikin@isuct.ru

6 Department of Physical and Colloidal Chemistry, Ivanovo State University of Chemistry and Technology, Sheremetevsky Avenue 7, 153000 Ivanovo, Russia; shlykov@isuct.ru

* Correspondence: pogonin@isuct.ru (A.E.P.); girichev@isuct.ru (G.V.G.); Tel.: +7-4932-30-0960 (A.E.P.); +7-4932-35-9874 (G.V.G.)

check for updates

Citation: Pogonin, A.E.; Otlyotov, A.A.; Minenkov, Y.; Semeikin, A.S.; Zhabanov, Y.A.; Shlykov, S.A.; Girichev, G.V. Molecular Structure of Nickel Octamethylporphyrin-Rare Experimental Evidence of a Ruffling Effect in Gas Phase. Int. J. Mol. Sci. 2022, 23, 320. https://doi.org/ 10.3390/ijms23010320

Academic Editor: Andrea Romeo

Received: 4 November 2021

Accepted: 23 December 2021

Published: 28 December 2021

Publisher's Note: MDPI stays neutral with regard to jurisdictional claims in published maps and institutional affiliations.

Copyright: (C) 2021 by the authors. Licensee MDPI, Basel, Switzerland. This article is an open access article distributed under the terms and conditions of the Creative Commons Attribution (CC BY) license (https:// creativecommons.org/licenses/by/ $4.0 /)$.

\begin{abstract}
The structure of a free nickel (II) octamethylporphyrin (NiOMP) molecule was determined for the first time through a combined gas-phase electron diffraction (GED) and mass spectrometry (MS) experiment, as well as through quantum chemical (QC) calculations. Density functional theory (DFT) calculations do not provide an unambiguous answer about the planarity or nonplanar distortion of the NiOMP skeleton. The GED refinement in such cases is non-trivial. Several approaches to the inverse problem solution were used. The obtained results allow us to argue that the ruffling effect is manifested in the NiOMP molecule. The minimal critical distance between the central atom of the metal and nitrogen atoms of the coordination cavity that provokes ruffling distortion in metal porphyrins is about $1.96 \AA$.
\end{abstract}

Keywords: molecular structure; ruffling distortion; porphyrin; quantum chemistry; nickel; electron diffraction

\section{Introduction}

Porphyrin metal complexes are the active core of many biochemical systems, e.g., hemoglobin, chlorophyll and vitamin $B_{12}$ [1,2]. An important source of porphyrins is oil, a ton of which can contain up to several kilograms of porphyrins, especially vanadyl-ion $\left(\mathrm{VO}^{2+}\right)$ and nickel ion $\left(\mathrm{Ni}^{2+}\right)$ complexes [2].

Porphyrin metal complexes are the active catalysts in chemical, electrochemical and photochemical processes, including the electroreduction of molecular oxygen, the anodic oxidation of sulfur dioxide, the cathodic reduction of nitrous oxide, the isomerization of unsaturated compounds, etc. [3]. Some etioporphyrin metal complexes are now considered to be potential radioprotective agents and stimulants of post-radiation rehabilitation [3]. Moreover, porphyrin metal complexes are promising agents for photodynamic therapy and in the production of basic film materials for photovoltaic devices [4,5], microelectronics [6,7] and electrochemical Gratzel cells (DSSC) [8]. A number of physico-chemical properties of porphyrin compounds that determine the features of their absorption and luminescent spectra should be taken into account in the screening of effective sensibilizators [9]. Theoretical calculations of electronic transitions and the HOMO-LUMO energy gap are currently 
being performed in order to discover substances that are potentially effective in solar batteries $[10,11]$. Due to their stability at high temperatures, porphyrin metal complexes can be used as dyes under extreme conditions [2].

Porphyrin metal complexes are important for environmental protection as they can serve as sensible chemical materials in the new generation of resistive gas sensors because they possess improved metrological characteristics [12]. The influence of a central metal atom on the gas-sensitive properties of porphyrin-based materials was studied by examining the etioporphyrin (EP) complexes of cobalt, nickel, copper, zinc, palladium and platinum [12-15]. A sensor performance depends not only on the individual characteristics of the molecules, but on the structure of sprayed layers obtained through thermal sublimation as well [12].

The structural investigations of metal porphyrins are dominated by density functional theory (DFT) calculations. As many transition metal species are of a multireference character, the applicability of a single determinant DFT approach is questioned for porphyrin metal complexes. Nevertheless, our recent study [16] concludes that the ground state of nickel(II) complex with tetrakis(1,2,5-thiadiazolo)porphyrazine is clearly singlereference. This suggests that the DFT approach is most likely valid for other nickel(II) macroheterocycles.

The solid-state structures of porphyrin metal complexes are commonly obtained from X-ray diffraction experiments. According to a thorough study of the structure of porphyrin metal complexes $[17,18]$, the distance from the center of the macrocycle cavity to the nitrogen atom of $2.01 \AA$ corresponds to the minimal steric strain of the porphyrin core. Strong deviations from these values occurring in the case of complexes that possess a metal ionic radius that does not correspond to the cavity size results in different types of macroheterocycle distortions. Another factor is responsible for the deformations that are originated in various substituents located on the periphery of the molecule $[19,20]$. Under distortions, the spatial crowding of bulky substituents decreases, leading to the minimization of the peripheral steric strain. Figure 1 demonstrates the main typical distortions of the porphyrin cycle generally described in terms of normal coordinates. The study of ruffling, saddling and doming distortions is especially important in connection with their manifestation in biological molecules [21]. An explicit correlation between macrocycle nonplanarity and physico-chemical properties has been noted in ref. [22].

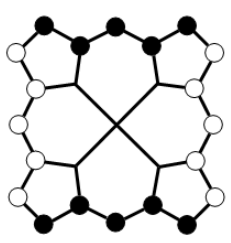

(a)

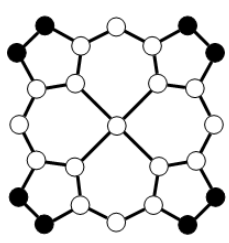

(b)

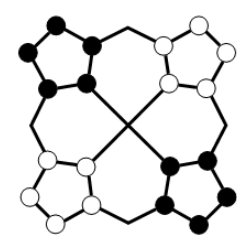

(c)

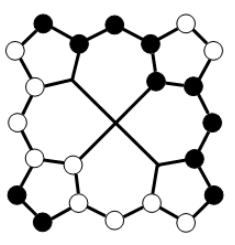

(d)

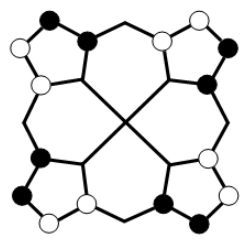

(e)

Figure 1. Possible types of porphyrin skeleton distortions: (a)—ruffling, (b)—dome shaped, (c)—saddle shaped, (d)—wave shaped, (e)-propeller shaped. A top view perpendicular to the macrocycle plane shows the positions of atoms relative to the plane of the porphyrin core: the light circle denotes an atom located above the plane, the dark circle denotes an atom located below the plane and the absence of a circle denotes the location of the atom in the plane of the porphyrin core.

Some factors affecting the manifestation of the ruffling distortion were analyzed [23] for porphyrin complexes with relatively small central ions, such as $\mathrm{Si}(\mathrm{IV}), \mathrm{P}(\mathrm{V}), \mathrm{Ge}(\mathrm{IV})$ and As (V). The threshold between the flat and distorted structures was concluded to correspond to the distance between the central atom and the nitrogen atoms of 2.00-2.02 $\AA$. The main structural parameter characterizing the degree of ruffling distortion is the dihedral angle $\chi\left(\mathrm{C}_{\alpha}-\mathrm{N} \cdots \mathrm{N}-\mathrm{C}_{\alpha}\right)$. In this case, a distortion of $20-30^{\circ}$ is often accompanied by small energy changes (less than $4 \mathrm{~kJ} \cdot \mathrm{mol}^{-1}$ ) indicating the extreme softness of this type of deformation. The authors of [23] also noted other structural parameters that change with 
the manifestation of the ruffling distortion of the macrocycle. For example, with increasing macrocyclic distortion, the bond angle $C_{\alpha}-C_{m}-C_{\alpha}$ tends to decrease, while the $C_{\beta}-C_{\beta}$ distance and the $\mathrm{C}_{\alpha}-\mathrm{N}-\mathrm{C}_{\alpha}$ angle tend to increase.

The DFT study of changes in the internal cavity within the series of the simplest porphyrin complexes $\mathrm{MP}(\mathrm{M}=\mathrm{Cr}, \mathrm{Mn}, \mathrm{Fe}, \mathrm{Co}, \mathrm{Ni}, \mathrm{Cu}, \mathrm{Zn})$ was carried out in ref. [24]. Short M-N distances (typical for nickel complexes) lead to ruffling distortion. The authors of [24] also consider the dependence of the size of the coordination cavity on the number of electrons of the metal atom, which can be explained in terms of the population of d-orbitals. The largest cavity size is observed in the case of the $\mathrm{MnP}$ that possesses a high spin $\mathrm{d}^{5}$ state. The addition or removal of an electron (Fe an $\mathrm{Cr}$ complexes) results in a decrease in the cavity size due to the absence of an electron on the $\mathrm{d}_{\mathrm{x} 2-\mathrm{y} 2}$ orbital. The shortest M-N bonds were found for the nickel porphyrin (NiP) singlet state, where eight electrons occupy four $\mathrm{d}$-orbitals, except for $\mathrm{d}_{\mathrm{x} 2-\mathrm{y} 2}$. In this case, the addition or removal of one electron $(\mathrm{Cu}, \mathrm{Co})$ leads to the enlargement of the $\mathrm{MN}_{4}$ fragment. The diamagnetic nature of nickel and zinc porphyrins are also experimentally well established [25-27].

According to the literature, nickel porphyrins exist in either flat [28-31] or rufflingdistorted [32-34] forms. In the triclinic crystal lattice, a molecule of nickel octaethylporphyrin (NiOEP) possesses a planar structure with $\mathrm{Ni}-\mathrm{N}$ distances in the range of $1.946-1.958 \AA[28,29]$, while in the tetragonal lattice a distorted structure with $r(\mathrm{Ni}-\mathrm{N})=1.929 \AA$ was found [34]. According to X-ray diffraction (XRD) and Raman spectroscopy investigation [31], the NiP molecule possesses a planar structure both in the crystal and in the solution, but the flat and distorted structures coexist in solutions of NiOEP and mesotetraphenylporphyrin (NiTPP) [31,35]. The work [31] concludes that the replacement of peripheral hydrogen atoms by another substituent shifts the conformational equilibrium towards a non-planar structure. The macrocycle distortions are manifested in a bathochromic shift in the Q band of the absorption spectra [36], but this effect is insignificantly small. In ref. [37] it was shown that with an increase in the level of macrocycle distortion, a decrease in the energy gap of LUMO-HOMO occurs. Several NiTPP derivatives exhibit the effect of the degree of distortion on the redox potentials of the compounds.

According to the quantum chemical (QC) study [38], the conformers of NiOEP, with different arrangements of ethyl groups, exhibit some degree of ruffling distortion. The $\mathrm{Ni}-\mathrm{N}$ distance is in the range of 1.96-1.97 $\AA$. The flat structure maximizes the $\pi$-overlap in the system and corresponds to large-sized coordination cavity. At the same time, the size of $\mathrm{Ni}^{2+}$ is too small to form strong $\mathrm{Ni}-\mathrm{N}$ bonds without the distortion of the planar macrocycle structure. Therefore, the equilibrium structures of porphyrin complexes with nickel are forced to achieve a balance between energy gains due to the shortening of the $\mathrm{Ni}-\mathrm{N}$ bond and losses due to ruffling distortion because of a decrease in the degree of delocalization. According to the calculations carried out in [38], the ruffling distortion of a macroheterocycle reduces the total energy by ca. $0.8 \mathrm{~kJ} \cdot \mathrm{mol}^{-1}$.

In the literature, there is a clear lack of data on the structure of free molecules of porphyrin metal complexes, while a number of studies focused on the structural determinations of phthalocyanine complexes using the gas electron diffraction (GED) method [39-42]. As for the porphyrins, the data on the gas-phase structures of the following compounds are available: copper (II) octamethylporphyrin (CuOMP) [43], copper(II) etioporphyrinII (CuEP-II) [44], tin(II) octamethylporphyrin (SnOMP) [45], zinc(II) etioporphyrin-II (ZnEP-II) [46] and cobalt(II) etioporphyrin-II (CoEP-II) [47]. Based on the experimental and theoretical results, it was concluded that the above-mentioned porphyrin complexes with zinc, copper and cobalt have a flat structure, despite the fact that $r(M-N)$ in the series decreases by almost $0.07 \AA$ from 2.042 (5) $\AA$ in ZnEP-II [46] to 1.976 (5) $\AA$ in CoEP-II [47], which is below the threshold value of $2.01 \AA$ [18]. Therefore, experimental studies of the gas-phase structures of nickel porphyrins with even shorter M-N distances are important for checking for a ruffling effect manifestation in porphyrins in a gas phase [47].

In the present contribution we report the results of the experimental GED and theoretical QC studies on nickel(II) 2,3,7,8,12,13,17,18-octamethylporphyrin (NiOMP, Figure 2). 


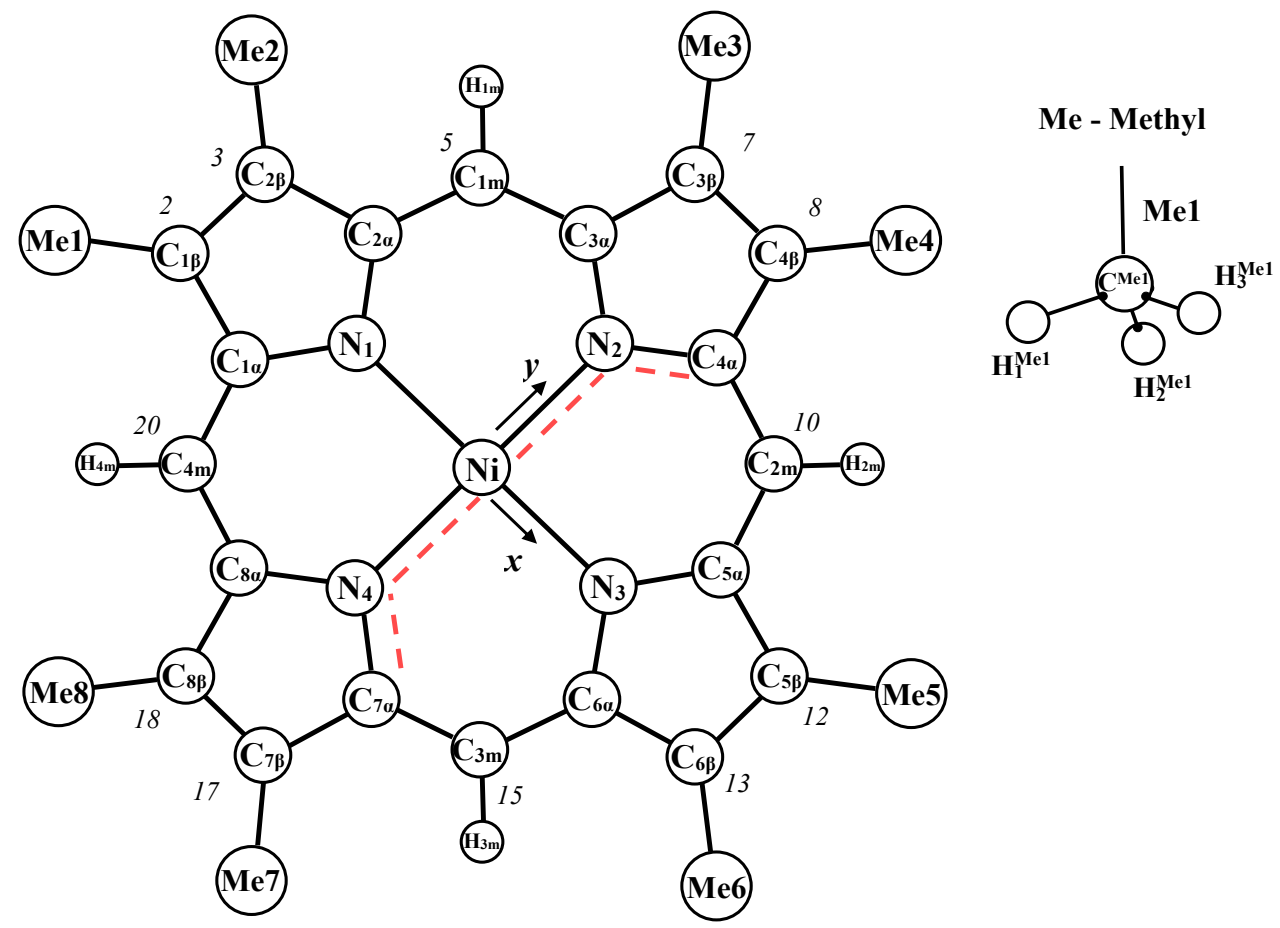

Figure 2. Molecular structure of NiOMP with atom numbering. The red dashed line shows an angle $\chi_{\text {ruf }}=\chi\left(C_{\alpha}-\mathrm{N} \cdots N-C_{\alpha}\right)$ quantifying the degree of ruffling distortion.

\section{Results}

The optimized structures from the QC calculations are given in the Supplementary Materials. Experimental and theoretical molecular scattering intensities $\mathrm{sM}(\mathrm{s})$ for the two nozzle-to-film distances are shown in Figure 3, along with the corresponding difference curves. The radial distribution curves and the difference curve are shown in Figure 4. We highlight the non-trivial structural analysis detailed in Sections 3.3 and 4.4.

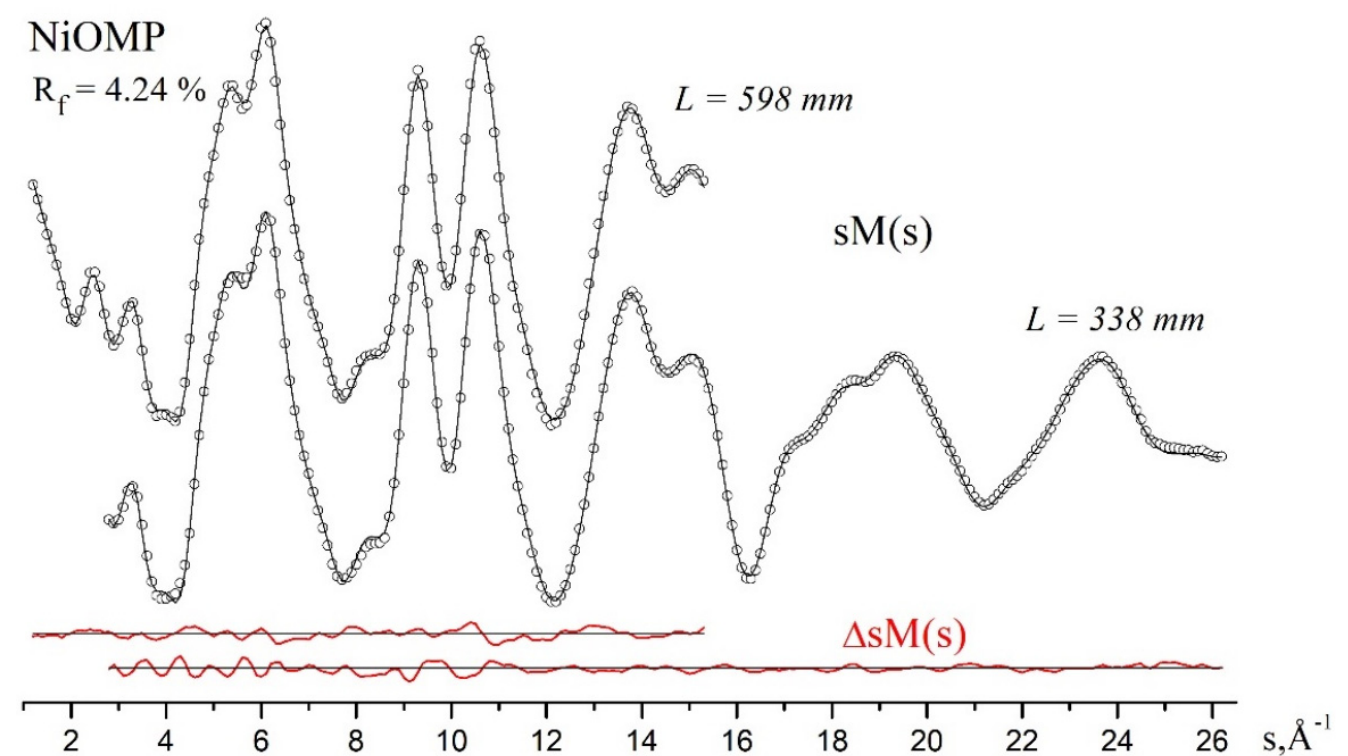

Figure 3. Experimental (cycles) and theoretical (black solid lines) molecular scattering intensities $\mathrm{sM}(\mathrm{s})$ and the difference curves $\Delta \mathrm{sM}(\mathrm{s})$ (red solid lines) for NiOMP: disagreement factor $\mathrm{R}_{\mathrm{f}}=4.24 \%$. 


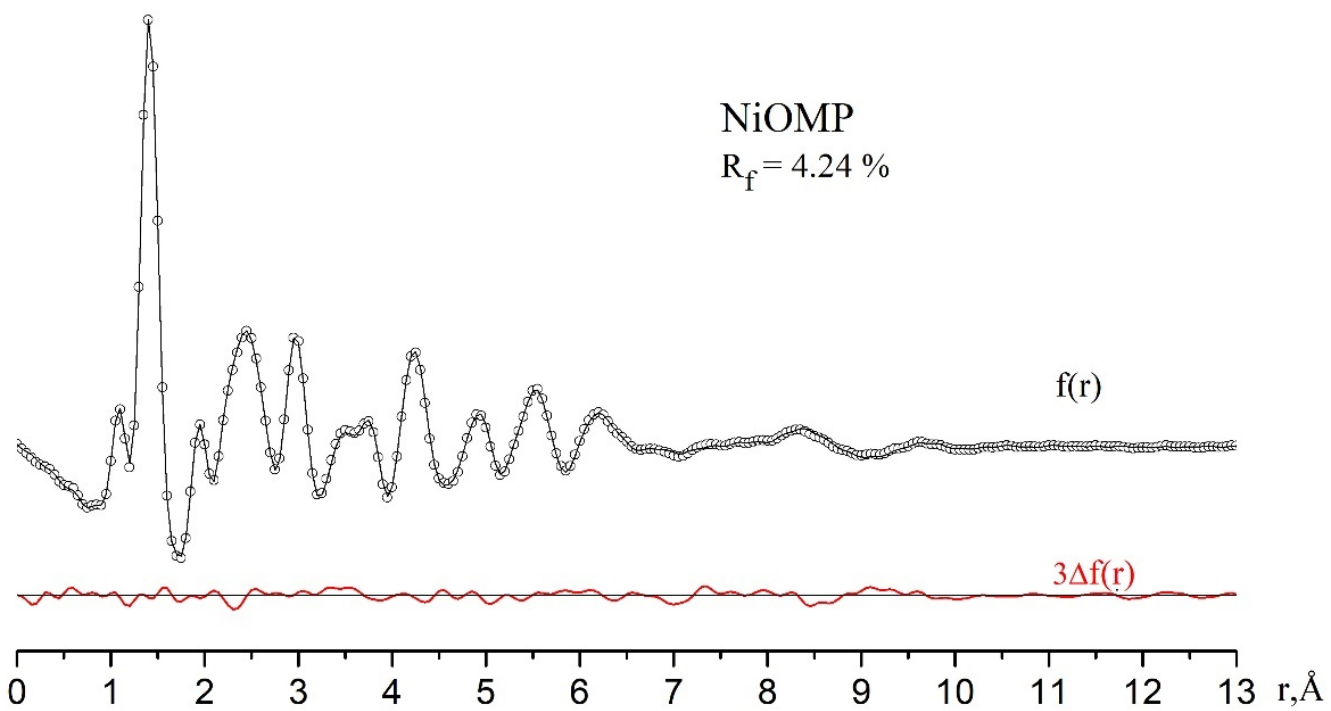

Figure 4. Experimental (cycles) and theoretical (black solid lines) radial distribution curves and the difference curve $3 \times \Delta f(r)$ (red solid lines) for NiOMP: disagreement factor $R_{f}=4.24 \%$.

\section{Discussion}

\subsection{Ambiguity in NiOMP Molecular Structure}

The performed QC calculations do not provide an unambiguous answer on the equilibrium spatial structure of the NiOMP molecule. The choice of the calculation level affects the prediction of the presence/absence of ruffling distortion in the macrocycle. Thus, according to the B3LYP calculations with the $6-31 G^{*}$ basis set, the NiOMP molecule possesses a nonplanar geometric structure with a $\mathrm{D}_{2 \mathrm{~d}}$ symmetry and a dihedral angle $\chi\left(\mathrm{C}_{\alpha}-\mathrm{N} \mathrm{N}-\mathrm{C}_{\alpha}\right) \approx 24^{\circ}$, while the planar structure of the $\mathrm{D}_{4 \mathrm{~h}}$ symmetry corresponds to the first-order saddle point on the potential energy surface (PES) and is $1.34 \mathrm{~kJ} \cdot \mathrm{mol}^{-1}$ higher in energy compared to the non-planar model. The distance between the nickel and nitrogen atoms in the $\mathrm{D}_{4 \mathrm{~h}}$ structure is larger than in the $\mathrm{D}_{2 \mathrm{~d}}$ structure by $0.016 \AA$. The structural parameters of the macroheterocyclic skeleton only slightly change with the extension of the basis set, while the Ni-N distance increases by $0.02-0.03 \AA$, and the flat $\mathrm{D}_{4 \mathrm{~h}}$ structure already corresponds to the minimum. The main structural parameters derived from the B3LYP calculations using various basis sets are listed in Table 1 . It is important to note that the use of the relativistic core potential for the description of the inner electron shells $\left(1 s^{2} 2 s^{2} 2 p^{6}\right)$ of the nickel atom does not lead to significant structural changes (Table 1).

Since the calculations with the B3LYP functional did not provide an unambiguous answer on the presence/absence of a ruffling distortion in the NiOMP molecule, we expanded the range of DFT-functionals used (B97D, PBE0 and M06 in combination with the $c c-p V T Z$ basis sets). According to the results of the calculations, the NiOMP molecule does not undergo a ruffling distortion. Considering the data given in Table 2, we note that in the series M06 $\rightarrow$ PBE0 $\rightarrow$ B3LYP $\rightarrow$ B97D $\rightarrow$ PBE, an increase in the related internuclear distances is observed, except for the Ni-N distance, which is smaller in the case of the PBE functional as compared to the B3LYP and B97D ones. It turned out that the set of theoretical methods listed above provides neither unique geometric nor electronic structures, predicting a different arrangement of frontier MOs (Figure 5). 
Table 1. Geometry parameters of NiOMP according to B3LYP calculations.

\begin{tabular}{|c|c|c|c|c|c|}
\hline \multirow{2}{*}{$\begin{array}{c}\text { Basis Set } \\
\begin{array}{c}\text { Equilibrium } \\
\text { Structure }\end{array}\end{array}$} & \multicolumn{2}{|c|}{$6-31 G^{*}, \mathrm{a}$} & \multirow{2}{*}{$\frac{p V T Z^{\mathrm{b}}}{\mathrm{D}_{4 \mathrm{~h}}}$} & \multirow{2}{*}{$\frac{c c-p V T Z{ }^{c}}{D_{4 h}}$} & \multirow{2}{*}{$\begin{array}{c}c c-p V T Z \\
\text { ECP10MDF } \\
\mathrm{D}_{4 \mathrm{~h}}\end{array}$} \\
\hline & $\mathrm{D}_{4 \mathrm{~h}}$ & $\mathrm{D}_{2 \mathrm{~d}}$ & & & \\
\hline$\omega_{\text {ruf }}{ }^{e}, \mathrm{~cm}^{-1}$ & 21(i) & 30 & 8 & 15 & 12 \\
\hline$\Delta \mathrm{E}^{\mathrm{f}}, \mathrm{kJ} \cdot \mathrm{mol}^{-1}$ & 1.38 & 0.00 & & & \\
\hline$\chi\left(C_{\alpha}-N \cdots N-C_{\alpha}\right),{ }^{\circ}$ & 0.0 & 24.1 & 0.0 & 0.0 & 0.0 \\
\hline $\mathrm{r}_{\mathrm{e}}(\mathrm{Ni}-\mathrm{N}), \AA$ & 1.958 & 1.942 & 1.977 & 1.974 & 1.972 \\
\hline$r_{e}(\mathrm{~N} \mathrm{~N}), \AA$ & 2.769 & 2.746 & 2.796 & 2.792 & 2.789 \\
\hline$r_{e}\left(N-C_{\alpha}\right), \AA$ & 1.379 & 1.378 & 1.374 & 1.371 & 1.371 \\
\hline$r_{e}\left(C_{\alpha}-C_{\beta}\right), \AA$ & 1.447 & 1.448 & 1.448 & 1.446 & 1.445 \\
\hline$r_{e}\left(C_{\alpha}-C_{m}\right), \AA$ & 1.379 & 1.381 & 1.379 & 1.377 & 1.376 \\
\hline$r_{e}\left(C_{\beta}-C_{\beta}\right), \AA$ & 1.365 & 1.367 & 1.363 & 1.361 & 1.361 \\
\hline$\varphi_{\mathrm{e}}\left(\mathrm{C}_{\alpha}-\mathrm{C}_{\mathrm{m}}-\mathrm{C}_{\alpha}\right),{ }^{\circ}$ & 123.9 & 123.4 & 124.6 & 124.6 & 124.5 \\
\hline
\end{tabular}

a $6-31 G^{*}-$ for all atoms; ${ }^{\text {b }} \mathrm{H}, \mathrm{C}, \mathrm{N}-p V T Z, \mathrm{Ni}-c c-p V T Z ;{ }^{\mathrm{c}} \mathrm{H}, \mathrm{C}, \mathrm{N}, \mathrm{Ni}-c c-p V T Z ;{ }^{\mathrm{d}} \mathrm{H}, \mathrm{C}, \mathrm{N}-c c-p V T Z, \mathrm{Ni}-$

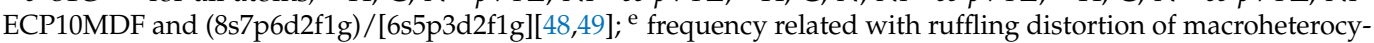
cle; ${ }^{\mathrm{f}}$ relative energy.

Table 2. Structural parameters of NiOMP according to DFT calculations, exploiting different functionals ${ }^{\mathrm{a}}$.

\begin{tabular}{ccccccc}
\hline DFT-Functionals & B3LYP & PBE0 & M06 & B97D & \multicolumn{2}{c}{ PBE } \\
\hline & $\mathbf{D}_{4 \mathbf{h}}$ & $\mathbf{D}_{4 \mathbf{h}}$ & $\mathbf{D}_{\mathbf{4 h}}$ & $\mathbf{D}_{\mathbf{4 h}}$ & $\mathbf{D}_{\mathbf{4 h}}$ & $\mathbf{D}_{\mathbf{2 d}}$ \\
\hline$\omega_{\text {ruf }}{ }^{\mathrm{b}}, \mathrm{cm}^{-1}$ & 15 & 7 & 13 & 11 & $14(\mathrm{i})$ & 21 \\
$\Delta \mathrm{E}, \mathrm{kJ} \cdot \mathrm{mol}^{-1 \mathrm{c}}$ & & & & & 0.30 & 0.00 \\
$\chi\left(\mathrm{C}_{\alpha}-\mathrm{N} \cdots \mathrm{N}^{-} \mathrm{C}_{\alpha}\right){ }^{\circ}$ & 0.0 & 0.0 & 0.0 & 0.0 & 0.0 & 17.8 \\
$\mathrm{r}_{\mathrm{e}}(\mathrm{Ni}-\mathrm{N}), \AA$ & 1.974 & 1.959 & 1.956 & 1.976 & 1.967 & 1.957 \\
$\mathrm{r}_{\mathrm{e}}(\mathrm{N} \cdots \mathrm{N}), \AA$ & 2.792 & 2.770 & 2.767 & 2.794 & 2.781 & 2.768 \\
$\mathrm{r}_{\mathrm{e}}\left(\mathrm{N}-\mathrm{C}_{\alpha}\right), \AA$ & 1.371 & 1.366 & 1.366 & 1.379 & 1.381 & 1.380 \\
$\mathrm{r}_{\mathrm{e}}\left(\mathrm{C}_{\alpha}-\mathrm{C}_{\beta}\right), \AA$ & 1.446 & 1.440 & 1.437 & 1.446 & 1.448 & 1.448 \\
$\mathrm{r}_{\mathrm{e}}\left(\mathrm{C}_{\alpha}-\mathrm{C}_{\mathrm{m}}\right), \AA$ & 1.377 & 1.373 & 1.371 & 1.380 & 1.380 & 1.381 \\
$\mathrm{r}_{\mathrm{e}}\left(\mathrm{C}_{\beta}-\mathrm{C}_{\beta}\right), \AA$ & 1.361 & 1.358 & 1.355 & 1.367 & 1.370 & 1.370 \\
$\varphi_{\mathrm{e}}\left(\mathrm{C}_{\alpha}-\mathrm{C}_{\mathrm{m}}-\mathrm{C}_{\alpha}\right){ }^{\circ}$ & 124.6 & 124.0 & 124.0 & 124.3 & 124.0 & 123.7 \\
\hline
\end{tabular}

$\overline{{ }^{a} c c-p V T Z}(\mathrm{H}, \mathrm{C}, \mathrm{N}, \mathrm{Ni})$ basis set $[50,51] ;{ }^{\mathrm{b}}$ frequency related to ruffling distortion of macroheterocycle; ${ }^{\mathrm{c}}$ relative energy.

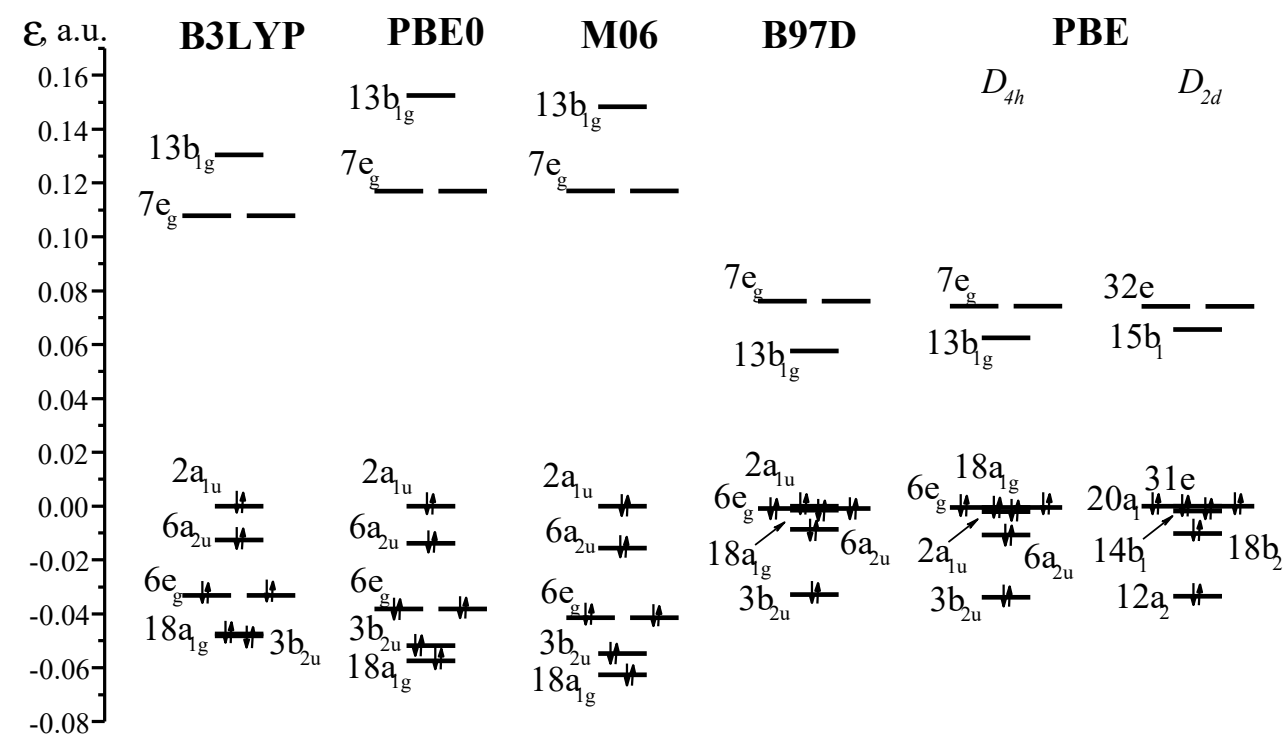

Figure 5. Molecular orbital diagrams for NiOMP according to different DFT methods. The energy of HOMO is chosen as zero level. 
According to the results of the B3LYP, PBE0 and M06 calculations, HOMO and HOMO-1 are the MOs of the macrocycle of $\mathrm{a}_{1 \mathrm{u}}$ and $\mathrm{a}_{2 \mathrm{u}}$ symmetry (Figure 5). The doubly degenerate orbitals of $e_{g}$ symmetry with a significant contribution $(\sim 30 \%)$ from the orbitals of the nickel atom $\left(\mathrm{d}_{\mathrm{xz}}, \mathrm{yz}\right)$ are lower in energy by $\sim 0.03 \mathrm{au}$. At the same time, according to PBE and B97D calculations, the lowest electronic state is characterized by the random degeneracy of the orbital of the $2 \mathrm{a}_{1 \mathrm{u}}, \mathrm{MO} 6 \mathrm{e}_{\mathrm{g}}$ macrocycle with a contribution from the nickel atom of $\sim 60 \%$ and $18 \mathrm{a}_{1 \mathrm{~g}} \mathrm{MO}$, which is the $\mathrm{d}_{\mathrm{z} 2} \mathrm{AO}$ of nickel. Despite the similar arrangement of the MOs according to the results of PBE and B97D calculations, in the first case, the ruffling-distorted structure with $\chi_{\text {ruf }}=17.8^{\circ}$ corresponds to the minimum, and in the second case, the structure of the molecule is flat. Schemes of some of the top occupied MOs are shown in Figure 6.

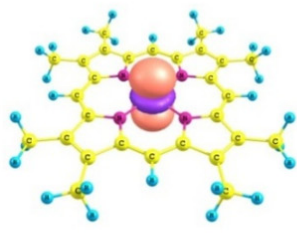

$18 \mathrm{a} 1 \mathrm{~g}$

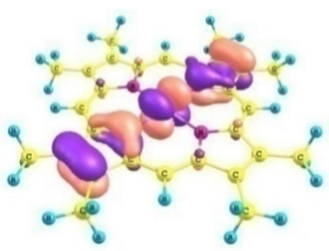

$6 e_{g}$

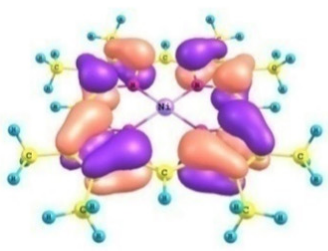

$2 \mathrm{a} 1 \mathrm{u}$

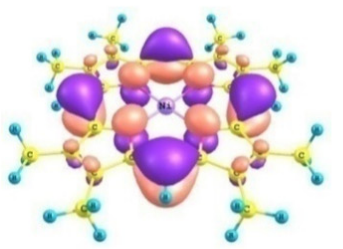

$6 a 2 u$

Figure 6. Molecular orbitals of NiOMP.

In order to evaluate the nonrigidity of the NiOMP along the ruffling vibrational mode molecule in comparison with similar complexes of copper and zinc, the PES profiles of ruffling distortion $\mathrm{U}\left(\mathrm{C}_{1 \alpha}-\mathrm{N}_{1}-\mathrm{N}_{3}-\mathrm{C}_{6 \alpha}\right)$ were evaluated (Figure 7) by scanning the torsion angle $\chi\left(\mathrm{C}_{1 \alpha}-\mathrm{N}_{1}-\mathrm{N}_{3}-\mathrm{C}_{6 \alpha}\right)$ while optimizing all other geometric parameters at the PBE/cCpVTZ and B3LYP/cc- $p V T Z$ theory levels. The potential along the ruffling-vibrational coordinate in the case of NiOMP is rather soft, which creates a fundamental difficulty in the determination of the optimal geometry. According to the DFT calculations, NiOMP can be considered to be a quasi-planar molecule.

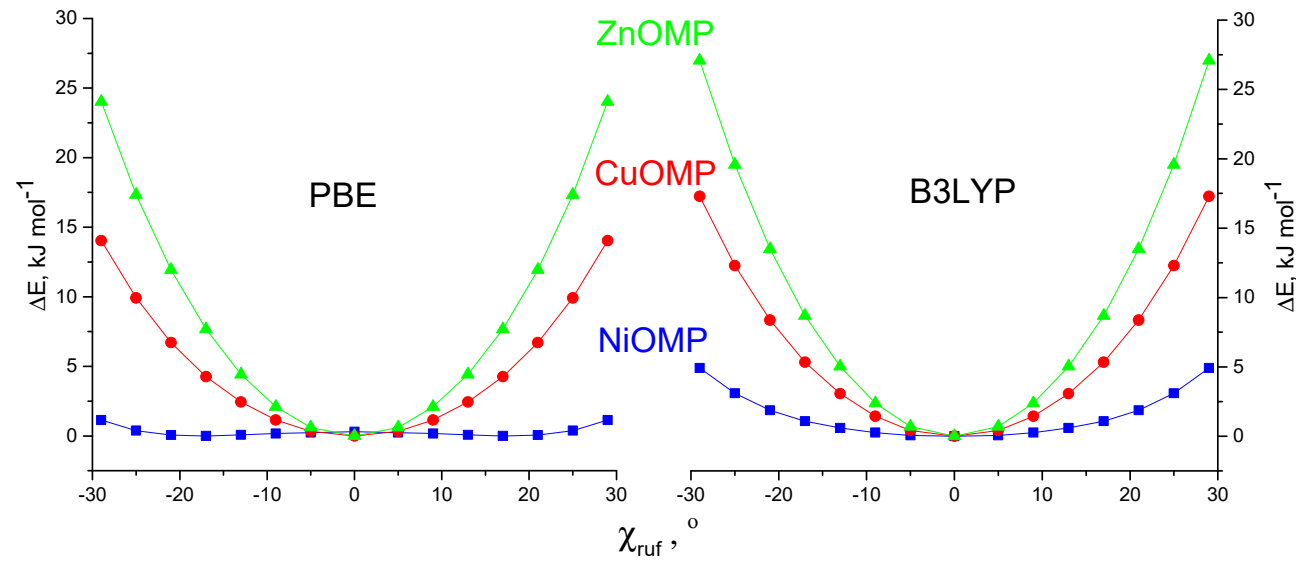

Figure 7. PES scans along $\chi_{\text {ruf }}=\chi\left(\mathrm{C}_{\alpha}-\mathrm{N} \cdots \mathrm{N}-\mathrm{C}_{\alpha}\right)$ angle for NiOMP (squares), CuOMP (circles), ZnOMP (triangles) according to PBE/cc- $p V T Z$ and B3LYP/cc- $p V T Z$.

It should be noted that this uncertainty in the structure is also a feature of the parent NiP compound: the B3LYP/ $(p V T Z, c c-p V T Z)$ calculations predict a flat $\mathrm{D}_{4 \mathrm{~h}}$ structure; in contrast, PBE calculations give the $\mathrm{D}_{2 \mathrm{~d}}$ structure, but the $\mathrm{D}_{4 \mathrm{~h}}$ structure (saddle point) has an energy that is only slightly higher than the energy of the $\mathrm{D}_{2 \mathrm{~d}}$ structure (less than $1 \mathrm{~kJ} \cdot \mathrm{mol}^{-1}$ ) (Table S2). According to the RI MP2 calculations, the NiP is characterized by a ruffling distortion with $\chi\left(\mathrm{C}_{\alpha}-\mathrm{N} \cdots \mathrm{N}-\mathrm{C}_{\alpha}\right)=33.7^{\circ}$, and the planar structure is higher in energy by 
$4.6 \mathrm{~kJ} \cdot \mathrm{mol}^{-1}$. To gain a deeper insight into the problem, we made a single-point DLPNO$\operatorname{CCSD}(\mathrm{T})$ calculation on the PBE/ $p V T Z(\mathrm{H}, \mathrm{C}, \mathrm{N}), c c-p V T Z(\mathrm{Ni})$ geometries of NiOMP. According to the DLPNO-CCSD $(T)$ calculations, the $\mathrm{D}_{2 \mathrm{~d}}$ structure of NiOMP turned out to be more stable than the $\mathrm{D}_{4 \mathrm{~h}}$ one by $0.6 \mathrm{~kJ} \cdot \mathrm{mol}^{-1}$.

\subsection{The Nature of Ruffling Distortion}

To simplify a description of the nature of the ruffling distortion in the porphyrin macrocycles, we considered the simplest nickel porphyrin, NiP. The QC calculations (B3LYP and PBE functionals, and basis sets of $p V T Z$ - for $\mathrm{H}, \mathrm{C}, \mathrm{N}, c c-p V T Z$ - for Ni) of the NiP molecule were carried out for both for the planar $\left(\mathrm{D}_{4 \mathrm{~h}}\right)$ structures and for ruffling-distorted $\left(D_{2 d}\right)$ structures at fixed values of the Ni-N bond lengths ranging from $1.90 \AA$ to $2.04 \AA$, with an optimization of all other geometric parameters. Based on the obtained results, the dependence of the structural parameters of the macrocycle on the length of the Ni-N bond was depicted in Figure 8.

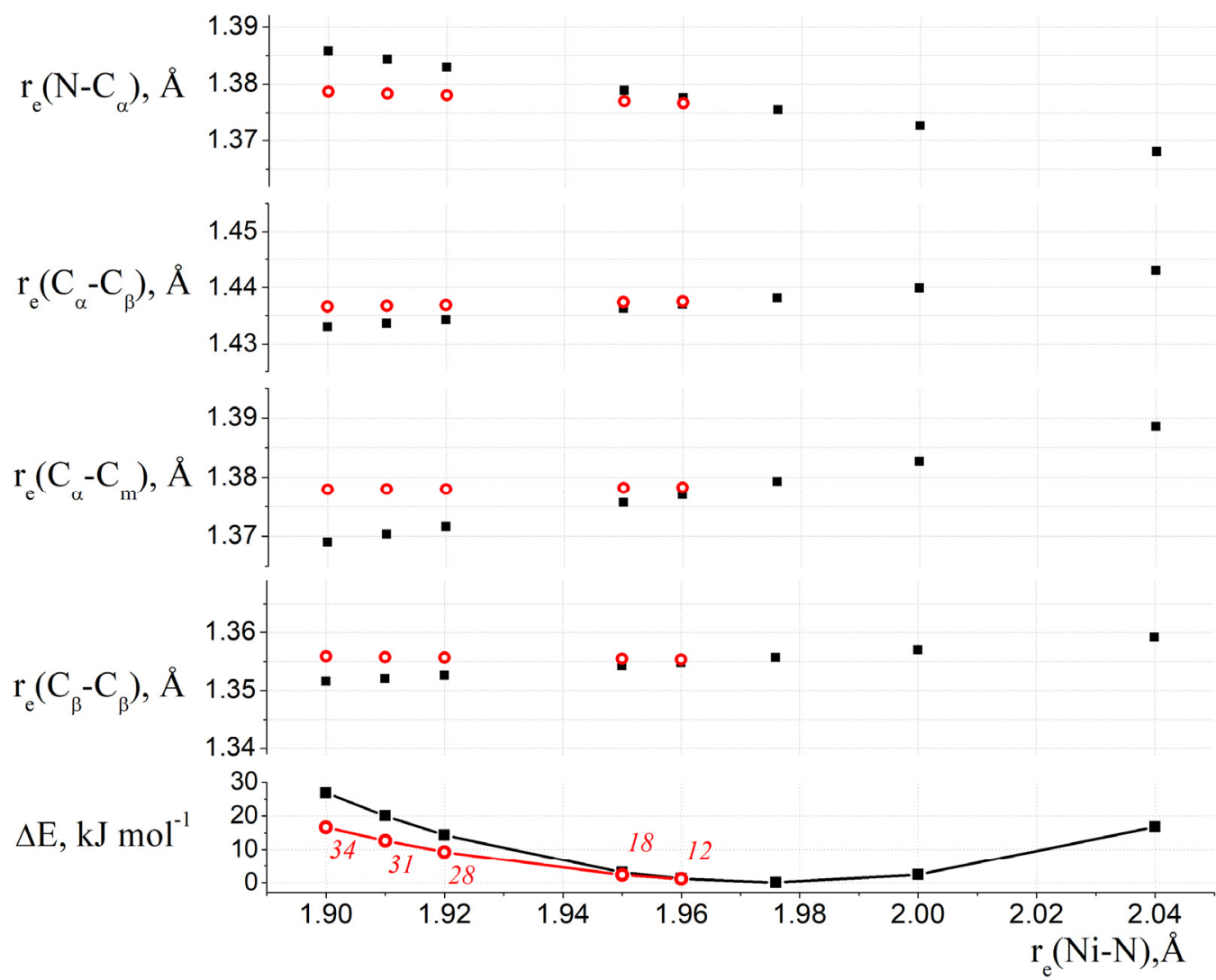

Figure 8. Internuclear distances $N-C_{\alpha}, C_{\alpha}-C_{m}, C_{\alpha}-C_{\beta}, C_{\beta}-C_{\beta}$ and relative energies of the structures vs. the internuclear distance of $\mathrm{Ni}-\mathrm{N}$ in the NiP molecule from the B3LYP calculations with the $p V T Z(\mathrm{H}, \mathrm{C}, \mathrm{N})$ and $c c-p V T Z(\mathrm{Ni})$ basis sets. Red circles-for ruffling distorted structures, black squares-for flat structures. Red italics numbers indicate values of $\chi_{\text {ruf }}=\chi\left(C_{\alpha}-N \cdots N-C_{\alpha}\right)$ for rufflingdistorted structures.

It is obvious that complexation is accompanied by a rearrangement of the porphyrin core. Thus, the equilibrium state is achieved as a compromise between the change in the macrocyclic cavity, which is necessary for optimal bond strength forming, and the forced macrocycle's rearrangement. In the case of the B3LYP calculations, for $\mathrm{r}_{\mathrm{e}}(\mathrm{Ni}-\mathrm{N}) \leq 1.96 \AA$, the studied planar structures correspond to saddle points on the PES. With an increase in the internuclear distance of Ni-N in the planar complex, the lengths of the $C_{\alpha}-C_{\beta}, C_{\alpha}-C_{m}$ and $\mathrm{C}_{\beta}-\mathrm{C}_{\beta}$ bonds increase along with the shortening of the $\mathrm{N}-\mathrm{C}_{\alpha}$ bond. An increase in the Ni-N distance to $1.976 \AA$ leads to a decrease in the energy of the molecule; i.e., it is 
accompanied by the stabilization of the entire complex. With a further increase in the Ni-N distance, an increase in the amount of energy occurs. The most energetically favorable structure is characterized by the following values of the bond lengths: $r_{e}\left(C_{\alpha}-C_{\beta}\right)=1.438 \AA$, $\mathrm{r}_{\mathrm{e}}\left(\mathrm{C}_{\beta}-\mathrm{C}_{\beta}\right)=1.356 \AA, \mathrm{r}_{\mathrm{e}}\left(\mathrm{C}_{\alpha}-\mathrm{C}_{\mathrm{m}}\right)=1.379 \AA, \mathrm{r}_{\mathrm{e}}\left(\mathrm{N}-\mathrm{C}_{\alpha}\right)=1.375 \AA$.

Figure 6 shows that the ruffling distortion makes it possible to almost achieve energetically favorable values of internuclear distances in a macrocycle with a shorter bond length between the $\mathrm{Ni}$ and $\mathrm{N}$ atoms. In this case, the energetically favorable values of internuclear distances $N-C_{\alpha}, C_{\alpha}-C_{m}, C_{\alpha}-C_{\beta}, C_{\beta}-C_{\beta}$ are achieved due to an increase in the ruffling angle $\mathrm{C}_{\alpha}-\mathrm{N} \cdots \mathrm{N}-\mathrm{C}_{\alpha}$ and correspond to the Ni-N distance being in the range of 1.90-1.96 $\AA$. It should be recalled that these B3LYP calculations predict a flat structure $\left(\mathrm{D}_{4 \mathrm{~h}}\right)$ of the macrocycle. Similar dependences were obtained from the analysis of the results of the PBE calculations (Figure S1) with the only differences being that: (a) the ruffling-distorted structure of $\mathrm{NiP}\left(\mathrm{D}_{2 \mathrm{~d}}\right)$ with an internuclear distance $\mathrm{r}_{\mathrm{e}}(\mathrm{Ni}-\mathrm{N})=1.956 \AA$ corresponds to the minimum on the PES and (b) a planar structure with an internuclear distance $r_{\mathrm{e}}(\mathrm{Ni}-\mathrm{N})=1.969 \AA$ has the lowest energy among the considered flat models and lies above the ruffling-distorted structure.

\subsection{The Determination of NiOMP Structure Using the GED Method}

The non-rigidity of the molecule along the ruffling coordinate is expressed by the shape of the PES along the dihedral angle $\chi\left(\mathrm{C}_{1 \alpha}-\mathrm{N}_{1}-\mathrm{N}_{3}-\mathrm{C}_{6 \alpha}\right)$ and leads to a low frequency of the corresponding vibration (Tables 3 and 4 ). The same was found for a saddle-shaped distortion in normal mode. Therefore, according to the B3LYP/ $p V T Z(\mathrm{H}, \mathrm{C}, \mathrm{N}), c c-p V T Z$ (Ni) calculations, $\omega_{\text {ruf }}=8 \mathrm{~cm}^{-1}, \omega_{\text {sad }}=20 \mathrm{~cm}^{-1}$. Within the framework of the SHRINK program formalism, such low frequencies lead to overestimated values of some of the vibrational corrections used in structural analysis. Thus, the vibrational corrections for the $\mathrm{Ni}-\mathrm{N}$ distance and the distances between the nonbonded atoms of the same pyrrole ring, calculated on the basis of the results of the B3LYP calculations, are $0.03-0.07 \AA$. This leads to a strong disagreement between the theoretical and experimental molecular scattering functions sM(s) within the least squares (LS) procedure (Table 3, variants no. 5 and no. 6). In these cases, the structure of the porphyrin cycle is strongly distorted, and the difference between the $r_{h 1}$ and $r_{e}$ parameters for the internuclear distances between the bound atoms reaches an unrealistic value of $0.02-0.10 \AA$.

Table 3. The degree of ruffling distortion according to the different schemes of structural refinement.

\begin{tabular}{|c|c|c|c|c|c|c|c|}
\hline $\begin{array}{l}\text { Variants of } \\
\text { LS Analysis }\end{array}$ & $V^{a}{ }^{a}$ & $\begin{array}{c}\text { Starting } \\
\text { Parameters }\end{array}$ & $\begin{array}{l}\omega_{\text {ruf }}, \\
\mathrm{cm}^{-1}\end{array}$ & $\begin{array}{l}\omega_{\text {sad }}, \\
\mathrm{cm}^{-1}\end{array}$ & $\mathbf{R}_{\mathrm{f}}, \%$ & $\chi_{\text {ruf }}$, deg. & $\begin{array}{c}\mathrm{r}_{\mathrm{h} 1} \\
(\mathrm{Ni}-\mathrm{N}), \AA\end{array}$ \\
\hline 1 & I & $\mathrm{D}_{2 \mathrm{~d}}-\mathrm{PBE}$ & $28^{c}$ & $19^{c}$ & 4.98 & 21.7 & $1.953(4)$ \\
\hline 2 & II & $\mathrm{D}_{2 \mathrm{~d}}-\mathrm{PBE}$ & $28^{\mathrm{c}}$ & $19^{c}$ & 4.32 & $14.6(46)$ & $1.952(4)$ \\
\hline 3 & I & $\mathrm{D}_{2 \mathrm{~d}}-\mathrm{PBE}$ & $70^{\mathrm{d}}$ & $19^{\mathrm{d}}$ & 4.27 & 21.7 & $1.948(4)$ \\
\hline 4 & II & $\mathrm{D}_{2 \mathrm{~d}}-\mathrm{PBE}$ & $70^{\mathrm{d}}$ & $19^{d}$ & 4.24 & $22.0(36)$ & $1.948(4)$ \\
\hline 5 & I & $\mathrm{D}_{4 \mathrm{~h}}-\mathrm{B} 3 \mathrm{LYP}$ & $8^{c}$ & $20^{c}$ & 16.93 & 0.0 & $2.056(11)$ \\
\hline 6 & II & $\mathrm{D}_{4 \mathrm{~h}}-\mathrm{B} 3 \mathrm{LYP}$ & $8^{c}$ & $20^{c}$ & 16.63 & $7.0(290)$ & $2.073(12)$ \\
\hline 7 & I & $\mathrm{D}_{4 \mathrm{~h}}-\mathrm{B} 3 \mathrm{LYP}$ & $28^{\mathrm{d}}$ & $20^{d}$ & 4.45 & 0.0 & $1.954(4)$ \\
\hline 8 & II & $\mathrm{D}_{4 \mathrm{~h}}-\mathrm{B} 3 \mathrm{LYP}$ & $28^{\mathrm{d}}$ & $20^{d}$ & 4.40 & $10.4(64)$ & $1.954(4)$ \\
\hline
\end{tabular}

a Scheme of independent variation of molecular parameters: I- $\chi_{\text {ruf }}$ was not refined, and was fixed at the calculated value, II- $\chi_{\text {ruf }}$ was refined; ${ }^{b}$ the method for calculation of vibrational amplitudes and corrections; ${ }^{c}$ calculated values; ${ }^{\mathrm{d}}$ refined values.

Since the disagreement factor $\mathrm{R}_{\mathrm{f}}$ obtained in the LS analysis using quantum chemical frequencies did not decrease below $\sim 16 \%$, we searched for the values of the wave numbers $\omega_{\text {ruf }}, \omega_{\text {sad }}$ corresponding to the minimum value of $R_{\mathrm{f}}$. For this purpose, an LS analysis was carried out repeatedly using the vibrational characteristics calculated using the vibration frequencies $\omega_{\text {ruf }}, \omega_{\text {sad }}$, which varied within the range of $8-100 \mathrm{~cm}^{-1}$. Table 3 summarizes the main results obtained using two variation schemes (fixing the ruffling angle obtained 
in the quantum chemical calculations and varying it) for different vibration frequencies $\omega_{\text {ruf }}, \omega_{\text {sad }}$.

Table 4. Structural parameters of nickel porphyrins according to QC, GED and XRD.

\begin{tabular}{|c|c|c|c|c|c|c|c|c|c|c|c|}
\hline Parameters & NiP & & & NiOMP. & & & $\begin{array}{l}\text { NiEP- } \\
\text { I }\end{array}$ & NiTMP & & NiOEP & \\
\hline & $\begin{array}{c}\text { XRD }^{a} \\
{[31]}\end{array}$ & $\begin{array}{c}\text { RI MP2 } \\
D_{2 d}^{b}\end{array}$ & $\begin{array}{c}\text { B3LYP c } \\
D_{4 h}\end{array}$ & $\begin{array}{c}\mathrm{PBE}^{\mathrm{c}} \\
\mathrm{D}_{4 \mathrm{~h}}\end{array}$ & $\begin{array}{c}\mathrm{PBE}^{\mathrm{c}} \\
\mathrm{D}_{2 \mathrm{~d}}\end{array}$ & $\begin{array}{l}\text { GED }^{d}, r_{h 1} \\
R_{f}=4.24 \%\end{array}$ & $\begin{array}{c}\text { XRD }^{\mathrm{e}} \\
{[52]}\end{array}$ & $\begin{array}{l}\operatorname{XRD}^{f} \\
{[30]}\end{array}$ & $\begin{array}{c}\text { XRD }^{\mathrm{e}} \\
{[34]}\end{array}$ & $\begin{array}{l}\text { XRD }^{\mathrm{e}} \\
{[28]}\end{array}$ & $\begin{array}{c}\text { XRD e } \\
\text { [29] }\end{array}$ \\
\hline$\chi\left(\mathrm{C}_{\alpha}-\mathrm{N} \cdots \mathrm{N}-\mathrm{C}_{\alpha}\right),{ }^{\circ}$ & 1.6 & 32.6 & 0.0 & 0.0 & 21.7 & $22.0(36)$ & 0.0 & 0.9 & 31.8 & 0.8 & 1.3 \\
\hline $\mathrm{r}(\mathrm{Ni}-\mathrm{N}), \AA$ & 1.951 & 1.897 & 1.977 & 1.970 & 1.956 & $1.948(4)$ & 1.957 & 1.953 & 1.930 & 1.952 & 1.958 \\
\hline $\mathrm{r}(\mathrm{N} \cdots \mathrm{N}), \AA$ & 2.759 & 2.683 & 2.796 & 2.786 & 2.766 & $2.755(6)$ & 2.770 & 2.763 & 2.729 & 2.760 & 2.769 \\
\hline $\mathrm{r}\left(\mathrm{N}-\mathrm{C}_{\alpha}\right), \AA$ & 1.379 & 1.375 & 1.374 & 1.383 & 1.382 & $1.380(4)$ & 1.396 & 1.384 & 1.386 & 1.385 & 1.376 \\
\hline$r\left(C_{\alpha}-C_{\beta}\right), \AA$ & 1.435 & 1.438 & 1.448 & 1.450 & 1.451 & $1.451(3)$ & 1.427 & 1.439 & 1.448 & 1.444 & 1.444 \\
\hline $\mathrm{r}\left(\mathrm{C}_{\alpha}-\mathrm{C}_{\mathrm{m}}\right), \AA$ & 1.371 & 1.377 & 1.379 & 1.382 & 1.384 & $1.384(3)$ & 1.406 & 1.378 & 1.372 & 1.364 & 1.371 \\
\hline$r\left(C_{\beta}-C_{\beta}\right), \AA$ & 1.347 & 1.365 & 1.363 & 1.372 & 1.373 & $1.373(3)$ & 1.335 & 1.334 & 1.363 & 1.332 & 1.346 \\
\hline $\mathrm{r}\left(\mathrm{C}_{\beta}-\mathrm{C}^{\mathrm{Me}}\right), \AA$ & - & 1.490 & 1.497 & 1.496 & 1.496 & $1.508(4)$ & 1.553 & - & - & - & - \\
\hline$r\left(C_{\beta}-C^{E t}\right), \AA$ & - & - & - & - & - & - & 1.553 & - & 1.501 & 1.504 & 1.495 \\
\hline $\mathrm{r}\left(\mathrm{C}_{1}-\mathrm{C}_{2}\right), \AA$ & - & - & - & - & - & - & & - & 1.507 & 1.526 & 1.506 \\
\hline$\varphi\left(\mathrm{Ni}-\mathrm{N}-\mathrm{C}_{\alpha}\right), \circ$ & 127.8 & 128.1 & 127.6 & 127.8 & 127.7 & $127.8(2)$ & 127.6 & 127.6 & 127.5 & 128.0 & 128.0 \\
\hline$\varphi\left(\mathrm{C}_{\alpha}-\mathrm{N}-\mathrm{C}_{\alpha}\right),{ }^{\circ}$ & 104.3 & 103.9 & 104.9 & 104.3 & 104.7 & 104.4(4) & 104.8 & 104.8 & 105.1 & 104.1 & 103.9 \\
\hline$\varphi\left(C_{\alpha}-C_{m}-C_{\alpha}\right)$, & 123.5 & 122.3 & 124.5 & 124.0 & 123.6 & $123.3(5)$ & 118.4 & 121.9 & 124.1 & 125.2 & 125.2 \\
\hline$\varphi\left(C_{\alpha}-C_{\beta}-C_{\beta}\right)$, & 106.8 & 106.1 & 106.3 & 106.3 & 106.3 & $106.1(4)$ & 107.9 & 107.4 & 106.8 & 107.2 & 106.5 \\
\hline
\end{tabular}

${ }^{a}$ Average values, $\mathrm{T}=127 \mathrm{~K} ;{ }^{\mathrm{b}}$ basis set $\mathrm{L} 2{ }^{\mathrm{c}}{ }^{\mathrm{b}}$ basis set $p V T Z(\mathrm{H}, \mathrm{C}, \mathrm{N}), c c-p V T Z(\mathrm{Ni}){ }^{\mathrm{d}}$ uncertainties for the bond lengths were estimated as $\left[\left(2.5 \sigma_{\mathrm{LS}}\right)^{2}+(0.002 \mathrm{r})^{2}\right]^{1 / 2}$ and for the bond angles as $3 \sigma_{\mathrm{LS}}$; ${ }^{\mathrm{e}}$ average values, $\mathrm{T}=295 \mathrm{~K}$; ${ }^{\mathrm{f}}$ average values, $\mathrm{T}=140 \mathrm{~K}$.

According to the LS analysis performed with the use of scheme II (Table 3$)\left(\omega_{\text {ruf }}=28 \mathrm{~cm}^{-1}\right.$, $\left.\omega_{\text {sad }}=19 \mathrm{~cm}^{-1}, \mathrm{PBE} / p V T Z(\mathrm{H}, \mathrm{C}, \mathrm{N}) c c-p V T Z(\mathrm{Ni})\right)$, the distance between the nickel and nitrogen atoms is $\mathrm{r}_{\mathrm{h} 1}(\mathrm{Ni}-\mathrm{N})=1.952 \AA$, the angle $\chi\left(\mathrm{C}_{\alpha}-\mathrm{N} \cdots \mathrm{N}-\mathrm{C}_{\alpha}\right)$ characterizing the degree of distortion is $14.6^{\circ}$ and the disagreement factor is $R_{f}=4.32 \%$. Freezing the quantum chemical value $\chi\left(\mathrm{C}_{\alpha}-\mathrm{N} \cdots \mathrm{N}-\mathrm{C}_{\alpha}\right)=21.7^{\circ}$ increases $\mathrm{R}_{\mathrm{f}}$ to $4.98 \%$, with the distances between the bonded atoms of the porphyrin core change not exceeding $0.002 \AA$. The optimal values of the vibration frequencies $\omega_{\text {ruf }}=70 \mathrm{~cm}^{-1}, \omega_{\text {sad }}=19 \mathrm{~cm}^{-1}$, found during their optimization, can reduce the disagreement down to $\mathrm{R}_{\mathrm{f}}=4.24 \%$.

At the final stage of the structural refinement of NiOMP, the results of six variants of the LS analysis $(1-4,7,8)$, shown in Table 3, were compared. The distances between the bonded atoms obtained during these variations are in good agreement with each other. Some difference in the value of the internuclear distance obtained with different variants of the LS analysis is observed for $C_{\beta}-C_{\beta}$. This is due to the difference between the quantum chemical differences $\left[r\left(C_{\alpha}-C_{\beta}\right)-r\left(C_{\beta}-C_{\beta}\right)\right]$ obtained in the PBE and B3LYP calculations and fixed during the $\mathrm{LS}$ analysis. The minimum disagreement factor is achieved in variant 4 (Table 3).

Based on the Hamilton statistical approach [53], it was checked whether the flat and ruffling-distorted structures of the NiOMP molecule are distinguishable. For this purpose, additional LS calculations were performed according to variants 2 and 4 (Table 3), in each of which the value of the dihedral angle $\chi\left(\mathrm{X}_{1}-\mathrm{Ni}-\mathrm{N}_{1}-\mathrm{C}_{1 \alpha}\right)$ was fixed. Figure 7 shows the relationship between the ratio $R_{f} / R_{f, m i n}$ of the disagreement factors and the ruffling angle $x\left(\mathrm{C}_{6 \alpha}-\mathrm{N}_{3}-\mathrm{N}_{1}-\mathrm{C}_{1 \alpha}\right)$, where $\mathrm{R}_{\mathrm{fmin}}$ is disagreement factor obtained in the LS analyses 2 and 4 (Table 3). In the first case (Figure 9a), the disagreement between experiment and theory decreases with a change in $\chi\left(\mathrm{C}_{6 \alpha}-\mathrm{N}_{3}-\mathrm{N}_{1}-\mathrm{C}_{1 \alpha}\right)$ from $0^{\circ}$ to $15^{\circ}$ and rapidly increases with a further increase in this parameter. Since the LS analysis was carried out using 377 experimental points ( $\mathrm{s}=1.2-15.3 \AA^{-1}, 2.8-26.2 \AA^{-1}$ with a step of $\Delta \mathrm{s}=0.1 \AA^{-1}$ ) and 22 independent parameters, the value of the Hamilton statistical criterion at a significance level of 0.05 is $R_{\mathrm{Ham}}=\mathrm{R}_{\mathrm{f}} / \mathrm{R}_{\mathrm{f} \text {, min }}=1.047$. In the case of a planar molecule, that is, at $\chi\left(\mathrm{C}_{6 \alpha}-\mathrm{N}_{3}-\mathrm{N}_{1}-\mathrm{C}_{1 \alpha}\right)=0^{\circ}$, the ratio $\mathrm{R}_{\mathrm{f}} / \mathrm{R}_{\mathrm{f}, \min }=1.051$ is almost equal to the Hamilton criterion $R_{\text {Ham }}$ (Figure 9a). In the case of using variant 4 of the LS analysis (Table 3), the ratio $\mathrm{R}_{\mathrm{f}} / \mathrm{R}_{\mathrm{f} \text {, min }}=1.24$ at $\chi\left(\mathrm{C}_{6 \alpha}-\mathrm{N}_{3}-\mathrm{N}_{1}-\mathrm{C}_{1 \alpha}\right)=0^{\circ}$ significantly exceeds the 
Hamilton criterion (Figure 7), which formally indicates a substantial preference of the ruffling-distorted structure for the NiOMP molecule over a flat one.

Additionally, an alternative approach to the GED inverse problem solution with the GedModule program [54] was used. This one involves the variation of the force constants scale factors used for the amplitudes and vibration corrections calculations instead of the variation of the vibrational amplitudes in the classic version of GED LS analysis. The details of the approach are described in ref. [54]. In the LS structural analysis, the geometric parameters and the force field obtained in the calculations PBE/ $p V T Z$ (structure of $\mathrm{D}_{2 \mathrm{~d}}$ symmetry) and B3LYP/ $p V T Z$ (planar structure of $\mathrm{D}_{4 \mathrm{~h}}$ symmetry) were taken as starting values. It should be noted that the use of the force field obtained for the planar structure in the $\mathrm{B} 3 \mathrm{LYP} / p V T Z$ calculations leads to slightly distorted structures (Table S3), whereas the structural analysis using a force field from $\mathrm{PBE} / p V T Z$ calculations gives a more distorted structure (Table S3).

Proving either the presence or absence of ruffling distortion using the GED method is a nontrivial task. Although, the fundamental difference in the shape of the dependences of $\mathrm{R}_{\mathrm{f}} / \mathrm{R}_{\mathrm{fmin}}$ on $\chi\left(\mathrm{C}_{\alpha}-\mathrm{N} \cdots \mathrm{N}-\mathrm{C}_{\alpha}\right)$ for the CoEP-II molecule [47] and for the NiOMP molecule makes it possible to state that the structure of NiOMP determined in the GED experiment is ruffling distorted.

In Table 4, the calculated structural parameters of NiOMP are compared with the experimental parameters of different nickel porphyrins obtained via XRD [28-31,34,52] and GED. The Ni-N internuclear distance of the free NiOMP molecule turned out to be almost equal to similar parameters according to an XRD analysis for ruffling-undistorted complexes. Despite this fact, it is necessary to bear in mind that the structural parameters obtained via the GED and XRD methods have different physical meanings [45]. The Ni-N bond length in the distorted NiOEP complex [34] is shorter by $0.02-0.03 \AA$ than in the planar nickel porphyrins in the crystalline phase and NiOMP in the gas phase. The shortening of the Ni-N distances favors the strengthening of the bonding between the $\mathrm{Ni}$ and $\mathrm{N}$ atoms, and in turn explains the observed ruffling distortion.

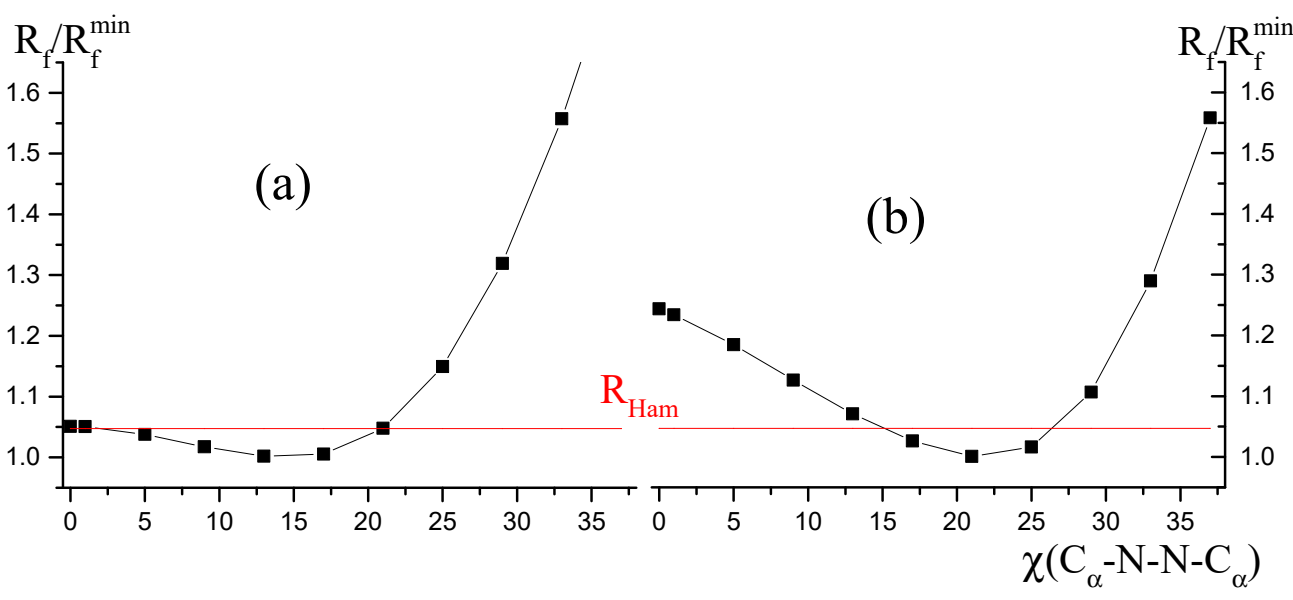

Figure 9. The ratio of disagreement factors $R_{f} / R_{f \min }$ as a function of the torsion angle $C_{\alpha}$ $\mathrm{N} \cdots \mathrm{N}-\mathrm{C}_{\alpha}$, responsible for ruffling distortion: (a)-using $\omega_{\text {ruf }}=28 \mathrm{~cm}^{-1}$ and $\omega_{\text {sad }}=19 \mathrm{~cm}^{-1}$, (b) $-\omega_{\text {ruf }}=70 \mathrm{~cm}^{-1}$ and $\omega_{\text {sad }}=19 \mathrm{~cm}^{-1} . R_{\mathrm{f}}$-factor of disagreement between experimental and theoretical molecular scattering intensities $\mathrm{sM}(\mathrm{s})$; $\mathrm{R}_{\mathrm{f} \mathrm{min}}-$ minimal value of disagreement factor obtained in the LS analysis; $\mathrm{R}_{\mathrm{Ham}}$-uncertainty according to Hamilton's statistical criterion [53] at significance level 0.05 .

\section{Materials and Methods}

\subsection{Synthesis}

For this process, $50 \mathrm{mg}(0.118 \mathrm{mmol})$ of 2,3,7,8,12,13,17,18-octamethylporphine was washed into a boiling solution of $0.5 \mathrm{~g}(1.94 \mathrm{mmol})$ of acetylacetonate nickel (II) in $30 \mathrm{~mL}$ 
of tetrachloroethane. After the complete washout, the solution was boiled for another $1 \mathrm{~h}$ and cooled. Water and $5 \mathrm{~mL}$ of acetic acid were added to the mixture and the solvent was distilled off with steam, the precipitate was filtered, washed with distilled water and dried in air at $70{ }^{\circ} \mathrm{C}$. The yield was $20 \mathrm{mg}$ (35.4\%). UV-vis $\lambda_{\max }, \mathrm{nm}(\lg \varepsilon): 553$ (4.46); 517 (4.93); 391 (5.28) (tetrachloroethane).

\subsection{Combined Gas-Pase Electron Diffraction/Mass-Spectrometric Experiment}

The combined gas-phase electron diffraction and mass spectrometric experiment was performed using the GED/MS apparatus [55,56]. An accurate wavelength of the electrons was determined from the diffraction patterns of polycrystalline ZnO. A sample of NiOMP was evaporated at 666(10) K, as measured by a W-Re 5/20 thermocouple, from a molybdenum effusion cell. The diffraction patterns were recorded on the Kodak Electron Image films SO-163 of $9 \times 12 \mathrm{~cm}^{2}$ size at two nozzle-to-plate distances (598 and $338 \mathrm{~mm}$ ). The conditions of GED/MS experiments are listed in Table 5. The optical densities of exposed films were recorded on a computer-controlled MD-100 (Carl Zeiss, Jena, GDR) setup [57]. For each film, a rectangular area of $10 \times 130 \mathrm{~mm}^{2}$ was scanned in a diagonal direction (33 equidistant lines with a step of $0.1 \mathrm{~mm}$ along each line).

Table 5. Parameters ${ }^{\text {a }}$ of the GED/MS experiment in synchronous mode for NiOMP.

\begin{tabular}{ccc}
\hline $\mathrm{L}, \mathrm{mm}$ & 598 & 338 \\
$\mathrm{I}, \mu \mathrm{A}$ & 0.96 & 1.37 \\
$\mathrm{U}_{\mathrm{acc}}, \mathrm{kV}$ & 71 & 73 \\
$\mathrm{~T}, \mathrm{~K} ;$ & $663(10)$ & $668(10)$ \\
$\mathrm{p}, \mathrm{Torr}$ & $2.9 \cdot 10^{-6}$ & $2.0 \cdot 10^{-6}$ \\
$\mathrm{t}, \mathrm{s}$ & 45 & 98 \\
$\mathrm{~N}$ & 6 & 6 \\
$\mathrm{~s}_{\min }-\mathrm{S}_{\max } \mathrm{b}, \AA^{-1}$ & $1.2-15.3$ & $2.8-26.2$ \\
\hline
\end{tabular}

a L-nozzle-to-film distance, I-primary electron beam current, $\mathrm{U}_{\text {acc }}$-accelerating voltage (approximate), T-effusion cell temperature, $\mathrm{p}$-residual pressure in diffraction chamber, $\mathrm{t}$-exposure time, $\mathrm{N}$-number of recorded films; ${ }^{\mathrm{b}}$ step $\Delta \mathrm{s}=0.1 \AA^{-1}$.

Simultaneously with registrations of the electron diffraction patterns, the mass spectra of the NiOMP vapors were recorded. The mass spectrum (Table S1) is typical for porphyrin complexes and is characterized by two groups of peaks corresponded to singly and doubly charged ions. Each group consisted of the parent ion and ions formed by consecutive removal of $-\mathrm{CH}_{3}$ groups. The recorded mass spectra contain no ions with a mass exceeding the mass of a single-charged molecular ion, which indicates the absence of dimeric forms and heavy volatile impurities. The mass spectra recorded during two independent experiments (with nozzle-to-plate distances of 338 and $598 \mathrm{~mm}$ ) demonstrate a good reproducibility of the ion current relative abundances.

\subsection{Quantum Chemical Calculations}

Within the current investigation, QC calculations of the molecular geometries and Hessian of the NiOMP were performed using the Gaussian 09 program package [58] within the framework of the DFT method with the following functionals: B3LYP, PBE, PBE0, M06 and B97D. In this work, a large number of calculations were carried out using various basis sets: (a) 6-31G* [59-62]; (b) $p V T Z$ [61,63-65] for C, N, H, cc-pVTZ [51] for $\mathrm{Ni}$; (c) $c c-p V T Z[51,64]$ for all atoms; (d) $c c-p V T Z-$ for $\mathrm{C}, \mathrm{N}, \mathrm{H}$, for describing the $\mathrm{Ni}$ atom, the effective core potential ECP10MDF [49] was used in combination with the basis (8s7p6d2f1g)/[6s5p3d2f1g] [48,49], taken from the site of the Stuttgart-Cologne group [66]. The QC calculations of the optimization geometric structure of the nickel porphyrins were performed using the program Priroda 9 [67] within the framework of the RI MP2 method and with the basis set L2.

The sophisticated DLPNO-CCSD(T) method [68-70], as implemented in the ORCA 4.0 code [71] for single-point calculations, was applied. The "TightPNO" DLPNO settings 
(TCutPairs $=10^{-5}$, TCutPNO $=10^{-7}$ and TCutMKN $=10^{-3}$ ) were used, as recommended, for applications where the most accurate values are targeted [72]. The sub-valence electrons on the nickel atom were correlated following the new ORCA 4 defaults [73,74]. The scalar relativistic effects were accounted for in the second-order scalar relativistic Douglas-KrollHess (DKH2) Hamiltonian [75]. The following all-electron, relativistically recontracted [76], triple- $\zeta$ correlation-consistent basis sets were utilized in the present work. Dunning's ccpVnZ-DK basis sets were applied to describe the hydrogen, carbon and nitrogen atoms [50]. The nickel atom was described with the correlation-consistent, polarized, weighted corevalence cc-pwcVTZ-DK basis sets of Balabanov and Peterson [51]. The correlation fitting basis sets def2-qzvpp/C developed by Hättig [77,78], required for the resolution of the identity (RI) approximation as a part of DLPNO scheme, were used.

\subsection{Structural Analysis}

The analysis of the electron diffraction intensities was performed using a modified KCED-35 program, which is similar to the program described in the paper [79]. The model of NiOMP (Figure 2) was described through 26 independent parameters $\left(X_{1}\right.$ is a dummy atom defining the $\mathrm{z}$ axis direction and $\mathrm{X}_{1}$ is perpendicular to the molecule):

Ten internuclear distances: Ni-N $\mathrm{N}_{1}, \mathrm{~N}_{1}-\mathrm{C}_{1 \alpha}, \mathrm{C}_{1 \alpha}-\mathrm{C}_{1 \beta}, \mathrm{C}_{1 \beta}-\mathrm{C}_{2 \beta}, \mathrm{C}_{2 \alpha}-\mathrm{C}_{1 \mathrm{~m}}, \mathrm{C}_{1 \mathrm{~m}}-\mathrm{H}_{1 \mathrm{~m}}$, $\mathrm{C}^{\mathrm{Me} 1}-\mathrm{C}_{1 \beta}, \mathrm{H}_{1}{ }^{\mathrm{Me} 1}-\mathrm{C}^{\mathrm{Me} 1}, \mathrm{H}_{2}{ }^{\mathrm{Me} 1}-\mathrm{C}^{\mathrm{Me} 1}, \mathrm{H}_{3}{ }^{\mathrm{Me} 1}-\mathrm{C}^{\mathrm{Me} 1}$;

Seven bond angles: Ni-N $\mathrm{N}_{1}-\mathrm{C}_{1 \alpha}, \mathrm{N}_{1}-\mathrm{C}_{1 \alpha}-\mathrm{C}_{1 \beta}, \mathrm{H}_{4 \mathrm{~m}}-\mathrm{C}_{4 \mathrm{~m}}-\mathrm{C}_{1 \alpha}, \mathrm{C}^{\mathrm{Me} 1}-\mathrm{C}_{1 \beta}-\mathrm{C}_{1 \alpha}, \mathrm{H}_{1} \mathrm{Me}_{-}$ $\mathrm{C}^{\mathrm{Me} 1}-\mathrm{C}_{1 \beta}, \mathrm{H}_{2}{ }^{\mathrm{Me} 1}-\mathrm{C}^{\mathrm{Me} 1}-\mathrm{C}_{1 \beta}, \mathrm{H}_{3}{ }^{\mathrm{Me} 1}-\mathrm{C}^{\mathrm{Me} 1}-\mathrm{C}_{1 \beta}$;

Nine torsion angles: $X_{1}-N i-N_{1}-C_{1 \alpha}, C_{1 \beta}-C_{1 \alpha}-N_{1}-N i, C_{1 \beta}-C_{1 \alpha}-C_{2 \beta}-N_{1}, C_{4 m}-C_{8 \alpha}-C_{1 \alpha}-$ $\mathrm{Ni}, \mathrm{H}_{4 \mathrm{~m}}-\mathrm{C}_{4 \mathrm{~m}}-\mathrm{C}_{8 \alpha}-\mathrm{C}_{1 \alpha}, \mathrm{C}^{\mathrm{Me} 1}-\mathrm{C}_{1 \beta}-\mathrm{C}_{1 \alpha}-\mathrm{N}_{1}, \mathrm{H}_{1}^{\mathrm{Me}}-\mathrm{C}^{\mathrm{Me} 1}-\mathrm{C}_{1 \beta}-\mathrm{C}_{1 \alpha}, \mathrm{H}_{2}{ }^{\mathrm{Me} 1}-\mathrm{C}^{\mathrm{Me} 1}-\mathrm{C}_{1 \beta}-\mathrm{H}_{1} \mathrm{Me} 1$, $\mathrm{H}_{3}{ }^{\mathrm{Me} 1}-\mathrm{C}^{\mathrm{Me} 1}-\mathrm{C}_{1 \beta}-\mathrm{H}_{1}{ }^{\mathrm{Me} 1}$.

The angles $\mathrm{N}_{1}-\mathrm{Ni}-\mathrm{X}_{1}, \mathrm{~N}_{4}-\mathrm{N}_{\mathrm{i}}-\mathrm{X}_{1}-\mathrm{N}_{1}$ are fixed at $90^{\circ}$ and the dihedral angles $\mathrm{N}_{3}-\mathrm{Ni}-\mathrm{X}_{1}-$ $\mathrm{N}_{1}$ are fixed at $180^{\circ}$.

In least-squares (LS) analysis, two schemes for the refinement of the structural parameters were carried out (see Table 6). In the first scheme, the coordinates determining the ruffling distortion of the macrocycle were not refined. The second scheme implies the refinement of coordinates describing the ruffling distortion. These independent geometric parameters were refined simultaneously with 13 groups of vibrational amplitudes corresponding to the different peaks on the radial distribution curve. The starting values of the vibration amplitudes and the vibrational corrections to the internuclear distances were calculated using the SHRINK program [80-82], as well as the starting values of the geometric parameters were taken from the results of the B3LYP and PBE calculations using the following basis sets: for $\mathrm{H}, \mathrm{C}, \mathrm{N}$-Dunning basis sets $[63,64]$ supplemented by polarized functions $p V T Z[61,65]$ (the set is referred to as the «GAMESS $p V T Z$ » in the EMSL basis set exchange [83,84]), for Ni-cc-pVTZ [51]. Our earlier studies [44,46] revealed that QC calculations using this combination of basis sets give good agreement with the experimental results at a comparatively low cost of computational resources.

Table 6. Two schemes of the independent variation of molecular parameters in the LS refinement of NiOMP.

\begin{tabular}{ccc}
\hline Molecular Parameters & Schemes of Independent Variation of Molecular Parameters & II \\
\hline $\begin{array}{c}\text { Bond lengths } \\
\text { Bond angles } \\
\text { Torsion angles }\end{array}$ & $\mathrm{Ni}-\mathrm{N}, \mathrm{N}-\mathrm{C}, \mathrm{C}-\mathrm{C}{ }^{\mathrm{a}}$ & $\mathrm{Ni}-\mathrm{N}, \mathrm{N}-\mathrm{C}, \mathrm{C}-\mathrm{C}$ a \\
$\mathrm{Ni}-\mathrm{N}_{1}-\mathrm{C}_{1 \alpha}, \mathrm{N}-\mathrm{C}_{1 \alpha}-\mathrm{C}_{1 \beta}$ & $\mathrm{Ni}-\mathrm{N}_{1}-\mathrm{C}_{1 \alpha}, \mathrm{N}_{1}-\mathrm{C}_{1 \alpha}-\mathrm{C}_{1 \beta}$ \\
a the differences between $\mathrm{C}_{\alpha}-\mathrm{C}_{\beta}, \mathrm{C}_{\beta}-\mathrm{C}_{\beta}, \mathrm{C}_{\alpha}-\mathrm{C}_{\mathrm{m}}$ bond lengths were fixed at the calculated values.
\end{tabular}

\section{Conclusions}

Ruffling distortion can manifest itself in porphyrin molecules when the central atom reduces the coordination cavity. This type of distortion reduces the changes in the internuclear distances in the porphyrin core that occur during complexation. The Ni-N distance is 
short enough and, therefore, the manifestation of ruffling distortion is possible in porphyrin complexes with $\mathrm{Ni}(\mathrm{II})$.

Theoretical calculations do not provide an unambiguous answer concerning the presence of ruffling distortion in the NiOMP molecule. The complexity of these studies is associated with the non-rigidity of the molecule along the "ruffling" coordinate.

Taking into account the shallow potential function of NiOMP along the ruffling coordinate, proving the presence or absence of ruffling distortion using the GED method is a challenging problem. Within this work, a large number of approaches to structural analysis were used. They differ from each other according to (a) the starting geometric parameters obtained by the different QC calculations, (b) the vibrational corrections and the starting vibrational amplitudes, (c) the scheme of independent variations of the molecular parameters and (d) the variants of the force field variations during structural analysis. Nevertheless, a comprehensive comparison of the GED results obtained for NiOMP, CuOMP [43] and CoEP-II [47], specifically the fundamental difference in the shape of the dependences of $\mathrm{R}_{\mathrm{f}} / \mathrm{R}_{\mathrm{fmin}}$ on distortion coordinate, allows us to state that the ruffling distortion takes place in the NiOMP free molecule.

Eventually, the ruffling distortion should be expected for the porphyrin metal complexes with M-N distance shorter than $1.96 \AA$.

Supplementary Materials: The following supporting information can be downloaded at https: //www.mdpi.com/article/10.3390/ijms23010320/s1.

Author Contributions: Conceptualization, G.V.G.; methodology, G.V.G., A.E.P. and Y.A.Z.; software, Y.A.Z.; investigation: A.E.P., Y.M., A.S.S., Y.A.Z., S.A.S. and G.V.G.; formal analysis, A.E.P.; resources, G.V.G.; writing —original draft preparation, A.E.P., A.A.O., S.A.S. and G.V.G.; writing—review and editing, A.E.P., A.A.O., S.A.S., Y.M. and G.V.G.; visualization, A.E.P.; supervision, G.V.G.; project administration, G.V.G.; funding acquisition, G.V.G. All authors have read and agreed to the published version of the manuscript.

Funding: This work was supported by the Russian Science Foundation (grant No 20-13-00359). Experimental data collection at early stage was supported by the Russian Foundation for Basic Research (grant 13-03-00975a).

Data Availability Statement: Not applicable.

Acknowledgments: The gas-phase electron diffraction/mass-spectrometric experiments were carried out using the GED/MS equipment (https://www.isuct.ru/department/ckp/structure/ged-ms, accessed date: 25 October 2021) of the resources of the Center for Shared Use of Scientific Equipment of the ISUCT (with the support of the Ministry of Science and Higher Education of Russia, grant No. 075-15-2021-671). We thank A.V. Belyakov for his help in conducting the calculations.

Conflicts of Interest: The authors declare no conflict of interest.

\section{References}

1. Kalyanasundaram, K. Photochemistry of Polypyridine and Porphyrin Complexes; Academic Press: London, UK, $1992 ;$ ISBN 9780123949929.

2. Berezin, B.D.; Enikolopyan, N.S. Metalloporphyrins; Nauka: Moscow, Russia, 1988. (In Russian)

3. Askarov, K.A.; Berezin, B.D.; Bystritskaya, E.V.; Golubchikov, O.A.; Koifman, O.I.; Kuzmitsky, V.A.; Mairanovsky, V.G.; Ponomarev, N.V.; Rish, M.A.; Smirnov, B.R.; et al. Porphyrins: Spectroscopy, Electrochemistry, Application; in Russian; Enikolopyan, N.S., Ed.; Nauka: Moscow, Russia, 1987.

4. Mao, H.; Deng, H.; Li, H.; Shen, Y.; Lu, Z.; Xu, H. Photosensitization of $\mathrm{TiO}_{2}$ semiconductor with porphyrin. J. Photochem. Photobiol. A Chem. 1998, 114, 209-212. [CrossRef]

5. Rochford, J.; Chu, D.; Hagfeldt, A.; Galoppini, E. Tetrachelate porphyrin chromophores for metal oxide semiconductor sensitization: Effect of the spacer length and anchoring group position. J. Am. Chem. Soc. 2007, 129, 4655-4665. [CrossRef]

6. Evershed, R.P.; Wolff, G.A.; Shaw, G.J.; Eglinton, G. Hydrogen chemical ionization mass spectrometry of metalloporphyrins. Org. Mass Spectrom. 1985, 20, 445-453. [CrossRef]

7. Kang, B.K.; Aratani, N.; Lim, J.K.; Kim, D.; Osuka, A.; Yoo, K.H. Length and temperature dependence of electrical conduction through dithiolated porphyrin arrays. Chem. Phys. Lett. 2005, 412, 303-306. [CrossRef]

8. Walter, M.G.; Rudine, A.B.; Wamser, C.C. Porphyrins and phthalocyanines in solar photovoltaic cells. J. Porphyr. Phthalocyanines 2010, 14, 759-792. [CrossRef] 
9. Mironov, A.F. Photodynamic cancer therapy-new effective method for the diagnosis and treatment of malignant tumors. Soros Educ. J. 1996, 8, 32-40. (In Russian)

10. Irfan, A.; Hina, N.; Al-Sehemi, A.G.; Asiri, A.M. Quantum chemical investigations aimed at modeling highly efficient zinc porphyrin dye sensitized solar cells. J. Mol. Model. 2012, 18, 4199-4207. [CrossRef] [PubMed]

11. Balanay, M.P.; Kim, D.H. DFT/TD-DFT molecular design of porphyrin analogues for use in dye-sensitized solar cells. Phys. Chem. Chem. Phys. 2008, 10, 5121-5127. [CrossRef]

12. Goldshtrakh, M.A.; Zavyalov, S.A.; Rumayntseva, V.D.; Ischenko, A.A. Electrophysical and gas sensitive properties of sublimated etioporphyrin layers. Izv. Vyss. Uchebn. Zaved. Khim. Khim. Tekhnol. [Russ. J. Chem. Chem. Tech. 2006, 49, 17-21. (In Russian)

13. Bahtin, A.V.; Goldshtrakh, M.A.; Dorofeev, S.G.; Ishenko, A.A.; Kononov, N.N.; Tarasov, Y.I. Molecular structure and gas-sensitive properties of copper (II) and zinc (II) ethioporphyrines. Izv. Vyss. Uchebn. Zaved Khim. Khim. Tekhnol. 2010, 53, 55-60. (In Russian)

14. Goldshtrakh, M.A.; Dorofeev, S.G.; Ishenko, A.A.; Kiselev, Y.M.; Kononov, N.N. Comparative analysis of the effects of photo exposure and thermal activation on the sensory properties of cobalt (II) etioporphyrin films. Russ. J. Phys. Chem. 2009, 83, 1960-1965.

15. Goldshtrakh, M.A.; Kononov, N.N.; Dorofeev, S.G.; Ischenko, A.A. Gas sensitivity of etioporphyrin metal complexes in thin films. J. Anal. Chem. 2009, 64, 1247. [CrossRef]

16. Zhabanov, Y.A.; Eroshin, A.V.; Ryzhov, I.V.; Kuzmin, I.A.; Finogenov, D.N.; Stuzhin, P.A. Molecular structure, thermodynamic and spectral characteristics of metal-free and nickel complex of tetrakis(1,2,5-thiadiazolo)porphyrazine. Molecules 2021, $26,2945$. [CrossRef] [PubMed]

17. Hoard, J.L. Stereochemistry of hemes and other metalloporphyrins. Science 1971, 174, 1295-1302. [CrossRef] [PubMed]

18. Hoard, J.L. Some aspects of metalloporphyrin stereochemistry. Ann. N. Y. Acad. Sci. 1973, 206, 18-31. [CrossRef]

19. Jentzen, W.; Simpson, M.C.; Hobbs, J.D.; Song, X.; Ema, T.; Nelson, N.Y.; Medforth, C.J.; Smith, K.M.; Veyrat, M.; Mazzanti, M.; et al. Ruffling in a series of nickel(II) meso-tetrasubstituted porphyrins as a model for the conserved ruffling of the heme of cytochromes c. J. Am. Chem. Soc. 1995, 117, 11085-11097. [CrossRef] [PubMed]

20. Barbee, J.; Kuznetsov, A.E. Revealing substituent effects on the electronic structure and planarity of Ni-porphyrins. Comput. Theor. Chem. 2012, 981, 73-85. [CrossRef]

21. Liptak, M.D.; Wen, X.; Bren, K.L. NMR and DFT Investigation of heme ruffling: Functional implications for cytochrome c. J. Am. Chem. Soc. 2010, 132, 9753-9763. [CrossRef]

22. Röder, B.; Büchner, M.; Rückmann, I.; Senge, M.O. Correlation of photophysical parameters with macrocycle distortion in porphyrins with graded degree of saddle distortion. Photochem. Photobiol. Sci. 2010, 9, 1152-1158. [CrossRef]

23. Vangberg, T.; Ghosh, A. A first-principles quantum chemical analysis of the factors controlling ruffling deformations of porphyrins: Insights from the molecular structures and potential energy surfaces of silicon, phosphorus, germanium, and arsenic porphyrins and of a peroxidas. J. Am. Chem. Soc. 1999, 121, 12154-12160. [CrossRef]

24. Kozlowski, P.M.; Bingham, J.R.; Jarzecki, A.A. Theoretical analysis of core size effect in metalloporphyrins. J. Phys. Chem. A 2008, 112, 12781-12788. [CrossRef]

25. Ake, R.; Gouterman, M. Porphyrins: XX. Theory for the states of Ni(d8) complexes. Theor. Chem. Acc. 1970, 17, 408-416. [CrossRef]

26. Hoffman, B.M. Triplet state electron paramagnetic resonance studies of zinc porphyrins and zinc-substituted hemoglobins and myoglobins. J. Am. Chem. Soc. 1975, 97, 1688-1694. [CrossRef]

27. Liao, M.-S.; Scheiner, S. Electronic structure and bonding in metal porphyrins, metal=Fe, Co, Ni, Cu, Zn. J. Chem. Phys. 2002, 117, 205-219. [CrossRef]

28. Brennan, T.D.; Scheidt, W.R.; Shelnutt, J.A. New crystalline phase of (octaethylporphinato) nickel (II): Effects of.pi.-.pi. interactions on molecular structure and resonance Raman spectra. J. Am. Chem. Soc. 1988, 110, 3919-3924. [CrossRef]

29. Cullen, D.L.; Meyer, E.F. Crystal and molecular structure of the triclinic form of 1,2,3,4,5,6,7,7-octaethylporphinatonickel(II). Comparison with the tetragonal form. J. Am. Chem. Soc. 1974, 96, 2095-2102. [CrossRef]

30. Gallucci, J.C.; Swepston, P.N.; Ibers, J.A. The structures of (5,10,15,20-tetramethylporphyrinato)nickel(II) and (5,10,15,20tetramethylchlorinato)nickel(II). Acta Crystallogr. Sect. B 1982, 38, 2134-2139. [CrossRef]

31. Jentzen, W.; Turowska-Tyrk, I.; Scheidt, W.R.; Shelnutt, J.A. Planar solid-state and solution structures of (porphinato) nickel (II) as determined by X-ray diffraction and resonance raman spectroscopy. Inorg. Chem. 1996, 35, 3559-3567. [CrossRef]

32. Anderson, K.K.; Hobbs, J.D.; Luo, L.; Stanley, K.D.; Quirke, J.M.E.; Shelnutt, J.A. Planar-nonplanar conformational equilibrium in metal derivatives of octaethylporphyrin and meso-nitrooctaethylporphyrin. J. Am. Chem. Soc. 1993, 115, 12346-12352. [CrossRef]

33. Kozlowski, P.M.; Rush, T.S.; Jarzecki, A.A.; Zgierski, M.Z.; Chase, B.; Piffat, C.; Ye, B.-H.; Li, X.-Y.; Pulay, P.; Spiro, T.G. DFT-SQM force field for nickel porphine: intrinsic ruffling. J. Phys. Chem. A 1999, 103, 1357-1366. [CrossRef]

34. Meyer Jnr, E. The crystal and molecular structure of nickel(II)octaethylporphyrin. Acta Crystallogr. Sect. B 1972, 28, 2162-2167. [CrossRef]

35. Alden, R.G.; Crawford, B.A.; Doolen, R.; Ondrias, M.R.; Shelnutt, J.A. Ruffling of nickel(II) octaethylporphyrin in solution. J. Am. Chem. Soc. 1989, 111, 2070-2072. [CrossRef]

36. Jentzen, W.; Unger, E.; Karvounis, G.; Shelnutt, J.A.; Dreybrodt, W.; Schweitzer-Stenner, R. Conformational properties of nickel (II) octaethylporphyrin in solution. 1. Resonance excitation profiles and temperature dependence of structure-sensitive raman lines. J. Phys. Chem. 1996, 100, 14184-14191. [CrossRef] 
37. Maji, S.; Sarkar, S. HOMO based two electrons and one-electron oxidation in planar and nonplanar methoxy-substituted nickel tetraphenylporphyrins. Inorganica Chim. Acta 2010, 363, 2778-2785. [CrossRef]

38. Stoll, L.K.; Zgierski, M.Z.; Kozlowski, P.M. Density functional theory analysis of nickel octaethylporphyrin ruffling. J. Phys. Chem. A 2002, 106, 170-175. [CrossRef]

39. Strenalyuk, T.; Samdal, S.; Volden, H.V. Molecular structure of phthalocyaninatotin (II) studied by gas-phase electron diffraction and high-level quantum chemical calculations. J. Phys. Chem. A 2008, 112, 10046-10052. [CrossRef]

40. Tverdova, N.V.; Girichev, G.V.; Giricheva, N.I.; Pimenov, O.A. Accurate molecular structure of copper phthalocyanine (CuN8C32H16) determined by gas-phase electron diffraction and quantum-chemical calculations. Struct. Chem. 2011, 22, 319-325. [CrossRef]

41. Tverdova, N.V.; Girichev, G.V.; Krasnov, A.V.; Pimenov, O.A.; Koifman, O.I. The molecular structure, bonding, and energetics of oxovanadium phthalocyanine: An experimental and computational study. Struct. Chem. 2013, 24, 883-890. [CrossRef]

42. Tverdova, N.V.; Pimenov, O.A.; Girichev, G.V.; Shlykov, S.A.; Giricheva, N.I.; Mayzlish, V.E.; Koifman, O.I. Accurate molecular structure of nickel phthalocyanine (NiN8C32H16): Gas-phase electron diffraction and quantum-chemical calculations. J. Mol. Struct. 2012, 1023, 227-233. [CrossRef]

43. Girichev, G.V.; Giricheva, N.I.; Golubchikov, O.A.; Mimenkov, Y.V.; Semeikin, A.S.; Shlykov, S.A. Octamethylporphyrin copper, C28H28N4Cu-A first experimental structure determination of porphyrins in gas phase. J. Mol. Struct. 2010, 978, 163-169. [CrossRef]

44. Pogonin, A.E.; Tverdova, N.V.; Ischenko, A.A.; Rumyantseva, V.D.; Koifman, O.I.; Giricheva, N.I.; Girichev, G.V. Conformation analysis of copper (II) etioporphyrin-II by combined gas electron diffraction/mass-spectrometry methods and DFT calculations. $J$. Mol. Struct. 2015, 1085, 276-285. [CrossRef]

45. Girichev, G.V.; Giricheva, N.I.; Koifman, O.I.; Minenkov, Y.V.; Pogonin, A.E.; Semeikin, A.S.; Shlykov, S.A. Molecular structure and bonding in octamethylporphyrin tin (ii), SnN 4 C 28 H 28. Dalt. Trans. 2012, 41, 7550-7558. [CrossRef] [PubMed]

46. Tverdova, N.V.; Pogonin, A.E.; Ischenko, A.A.; Rumyantseva, V.D.; Koifman, O.I.; Giricheva, N.I.; Girichev, G.V. Combined gas-phase electron diffraction/mass spectrometry and DFT study of the molecular structure of zinc (II) etioporphyrin-II. Struct. Chem. 2015, 26, 1521-1530. [CrossRef]

47. Pogonin, A.E.; Otlyotov, A.A.; Tverdova, N.V.; Ischenko, A.A.; Rumyantseva, V.D.; Koifman, O.I.; Girichev, G.V. Molecular structure of cobalt (II) etioporphyrin-II determined by combined gas-phase electron diffraction/mass-spectrometry and quantum chemical calculations: Searching a ruffling and saddling effects. J. Mol. Struct. 2020, 1216, 128319. [CrossRef]

48. Martin, J.M.L.; Sundermann, A. Correlation consistent valence basis sets for use with the Stuttgart-Dresden-Bonn relativistic effective core potentials: The atoms Ga-Kr and In-Xe. J. Chem. Phys. 2001, 114, 3408-3421. [CrossRef]

49. Dolg, M.; Wedig, U.; Stoll, H.; Preuss, H. Energy-adjusted ab initio pseudopotentials for the first row transition elements. J. Chem. Phys. 1987, 86, 866-872. [CrossRef]

50. Dunning, T.H. Gaussian basis sets for use in correlated molecular calculations. I. The atoms boron through neon and hydrogen. J. Chem. Phys. 1989, 90, 1007-1023. [CrossRef]

51. Balabanov, N.B.; Peterson, K.A. Systematically convergent basis sets for transition metals. I. All-electron correlation consistent basis sets for the 3D elements Sc-Zn. J. Chem. Phys. 2005, 123, 64107. [CrossRef]

52. Fleischer, E.B. The structure of nickel etioporphyrin-I. J. Am. Chem. Soc. 1963, 85, 146-148. [CrossRef]

53. Hamilton, W.C. Significance tests on the crystallographic R factor. Acta Crystallogr. 1965, 18, 502-510. [CrossRef]

54. Zhabanov, Y.A.; Pogonin, A.E. An alternative approach to structural analysis for gas electron diffraction method. Comput. Theor Chem. 2018, 1123, 149-153. [CrossRef]

55. Girichev, G.V.; Utkin, A.N.; Revichev, Y.F. Modernization of the EMR-100 setup for the studies of gases. Prib. Tekh. Eksp. 1984, 27, 187-190.

56. Girichev, G.V.; Shlykov, S.A.; Revichev, Y.F. Apparatus for study of molecular structure of valence-unsaturated compounds. Prib. Tekh. Eksp. 1986, 29, 167-169.

57. Girichev, E.G.; Zakharov, A.V.; Girichev, G.V.; Bazanov, M.I. Automation of a physicochemical experiment: Photometry and voltammetry. Izv. Vysh. Uchebn. Zaved. Tekst. Prom. 2000, 2, 142-146.

58. Frisch, M.J.; Trucks, G.W.; Schlegel, H.B.; Scuseria, G.E.; Robb, M.A.; Cheeseman, J.R.; Scalmani, G.; Barone, V.; Mennucci, B.; Petersson, G.A.; et al. Gaussian 09; Revision D.02.; Gaussian, Inc.: Wallingford, CT, USA, 2009.

59. Ditchfield, R.; Hehre, W.J.; Pople, J.A. Self-consistent molecular-orbital methods. IX. An extended gaussian-type basis for molecular-orbital studies of organic molecules. J. Chem. Phys. 1971, 54, 724-728. [CrossRef]

60. Hehre, W.J.; Ditchfield, K.; Pople, J.A. Self-consistent molecular orbital methods. XII. Further extensions of gaussian-type basis sets for use in molecular orbital studies of organic molecules. J. Chem. Phys. 1972, 56, 2257-2261. [CrossRef]

61. Hariharan, P.C.; Pople, J.A. The influence of polarization functions on molecular orbital hydrogenation energies. Theor. Chim. Acta 1973, 28, 213-222. [CrossRef]

62. Rassolov, V.A.; Pople, J.A.; Ratner, M.A.; Windus, T.L. 6-31G* basis set for atoms K through Zn. J. Chem. Phys. 1998, 109, 1223-1229. [CrossRef]

63. Huzinaga, S. Gaussian-Type Functions for polyatomic systems. I. J. Chem. Phys. 1965, 42, 1293-1302. [CrossRef]

64. Dunning, T.H. Gaussian basis functions for use in molecular calculations. III. Contraction of (10s6p) atomic basis sets for the first-row atoms. J. Chem. Phys. 1971, 55, 716-723. [CrossRef] 
65. Urban, M.; Kellö, V.; Čársky, P. Polarization functions for gaussian basis sets for the first row atoms. Theor. Chim. Acta 1977, 45, 205-213. [CrossRef]

66. Stuttgart/Cologne Energy-Consistent (ab initio) Pseudopotentials Suitable for Wavefunction-Based and Density Functional Calculations. Available online: http:/ / www.tc.uni-koeln.de/PP/index.en.html (accessed on 14 September 2013).

67. Laikov, D.N.; Ustynyuk, Y.A. PRIRODA-04: A quantum-chemical program suite. New possibilities in the study of molecular systems with the application of parallel computing. Russ. Chem. Bull. 2005, 54, 820-826. [CrossRef]

68. Riplinger, C.; Neese, F. An efficient and near linear scaling pair natural orbital based local coupled cluster method. J. Chem. Phys. 2013, 138, 34106. [CrossRef] [PubMed]

69. Riplinger, C.; Sandhoefer, B.; Hansen, A.; Neese, F. Natural triple excitations in local coupled cluster calculations with pair natural orbitals. J. Chem. Phys. 2013, 139, 134101. [CrossRef] [PubMed]

70. Riplinger, C.; Pinski, P.; Becker, U.; Valeev, E.F.; Neese, F. Sparse maps-A systematic infrastructure for reduced-scaling electronic structure methods. II. Linear scaling domain based pair natural orbital coupled cluster theory. J. Chem. Phys. 2016, 144, 24109. [CrossRef]

71. Neese, F. Software update: The ORCA program system, version 4.0. Wiley Interdiscip. Rev. Mol. Sci. 2018, 8, e1327. [CrossRef]

72. Liakos, D.G.; Sparta, M.; Kesharwani, M.K.; Martin, J.M.L.; Neese, F. Exploring the accuracy limits of local pair natural orbital coupled-cluster theory. J. Chem. Theory Comput. 2015, 11, 1525-1539. [CrossRef]

73. Minenkov, Y.; Bistoni, G.; Riplinger, C.; Auer, A.A.; Neese, F.; Cavallo, L. Pair natural orbital and canonical coupled cluster reaction enthalpies involving light to heavy alkali and alkaline earth metals: The importance of sub-valence correlation. Phys. Chem. Chem. Phys. 2017, 19, 9374-9391. [CrossRef]

74. Bistoni, G.; Riplinger, C.; Minenkov, Y.; Cavallo, L.; Auer, A.A.; Neese, F. Treating subvalence correlation effects in domain based pair natural orbital coupled cluster calculations: An out-of-the-box approach. J. Chem. Theory Comput. 2017, 13, 3220-3227. [CrossRef]

75. Reiher, M.; Wolf, A. Exact decoupling of the Dirac Hamiltonian. II. The generalized Douglas-Kroll-Hess transformation up to arbitrary order. J. Chem. Phys. 2004, 121, 10945-10956. [CrossRef]

76. De Jong, W.A.; Harrison, R.J.; Dixon, D.A. Parallel Douglas-Kroll energy and gradients in NWChem: Estimating scalar relativistic effects using Douglas-Kroll contracted basis sets. J. Chem. Phys. 2001, 114, 48-53. [CrossRef]

77. Hättig, C. Optimization of auxiliary basis sets for RI-MP2 and RI-CC2 calculations: Core-valence and quintuple-zeta basis sets for $\mathrm{H}$ to Ar and QZVPP basis sets for Li to Kr. Phys. Chem. Chem. Phys. 2005, 7, 59-66. [CrossRef]

78. Hellweg, A.; Hättig, C.; Hoefener, S.; Klopper, W. Optimized accurate auxiliary basis sets for RI-MP2 and RI-CC2 calculations for the atoms Rb to Rn. Theor. Chem. Acc. 2007, 117, 587-597. [CrossRef]

79. Andersen, B.; Seip, H.M.; Strand, T.G.; Stolevik, R. Procedure and computer programs for the structure determination of gaseous molecules from electron diffraction data. Acta Chem. Scand. 1969, 23, 3224-3234. [CrossRef]

80. Sipachev, V.A. Calculation of shrinkage corrections in harmonic approximation. J. Mol. Struct. Theochem. 1985, $22,143-151$. [CrossRef]

81. Sipachev, V.A. Vibrational effects in diffraction and microwave experiments: A start on the problem. Adv. Mol. Struct. Res. 1999, 5, 263-311.

82. Sipachev, V.A. Local centrifugal distortions caused by internal motions of molecules. J. Mol. Struct. 2001, 567-568, 67-72. [CrossRef]

83. Feller, D. The role of databases in support of computational chemistry calculations. J. Comput. Chem. 1996, 17, 1571-1586. [CrossRef]

84. Schuchardt, K.L.; Didier, B.T.; Elsethagen, T.; Sun, L.; Gurumoorthi, V.; Chase, J.; Li, J.; Windus, T.L. Basis set exchange: A community database for computational sciences. J. Chem. Inf. Model. 2007, 47, 1045-1052. [CrossRef] 